\title{
Direct and simultaneous observation of transcription and chromosome architecture in Drosophila embryos with Hi-M
}

5

Andrés M. Cardozo Gizzi ${ }^{1,+}$, Sergio M. Espinola ${ }^{1}$, Julian Gurgo ${ }^{1}$, Christophe Houbron $^{1}$, Jean-Bernard Fiche ${ }^{1}$, Diego I. Cattoni ${ }^{1}$, Marcelo Nollmann ${ }^{1, \#}$

${ }^{1}$ Centre de Biochimie Structurale, CNRS UMR 5048, INSERM U1054, Université de Montpellier, 60 rue de Navacelles, 34090, Montpellier, France

+ present address: CIQUIBIC (CONICET) - Departamento de Química Biológica Ranwel Caputto, Facultad de Ciencias Químicas, Universidad Nacional de Córdoba, Haya de la Torre y Medina Allende, Ciudad Universitaria, 5000, Córdoba, Argentina.

\# To whom correspondence should be addressed:

Marcelo Nollmann: marcelo.nollmann@cbs.cnrs.fr 


\begin{abstract}
Simultaneous observation of 3D chromatin organization and transcription at the single cell level and with high spatial resolution may hold the key to unveil the mechanisms regulating embryonic development, cell differentiation and even disease. We have recently developed a novel technology, Hi-M, that allows for the sequential labeling, 3D imaging and localization of multiple genomic DNA loci together with RNA expression in single cells within whole, intact Drosophila embryos. Importantly, Hi-M enables simultaneous detection of RNA status and chromosome organization without sample unmounting and probe re-hybridization. Here, we provide a step-by-step protocol describing the design of probes, the preparation of samples, the stable immobilization of embryos into microfluidics chambers, and the complete procedure for image acquisition. The combined RNA/DNA FISH procedure takes 4-5 days including embryo collection. In addition, we describe image analysis software to segment nuclei, detect genomic spots, correct for drift and produce Hi-M matrices. A typical Hi-M experiment takes 1-2 days to complete all rounds of labeling and imaging and 4 additional days for image analysis. All these procedures can be accomplished by a competent graduate student or experienced technician. This technology can be easily expanded to investigate cell differentiation in cultured cells, or organization of chromatin within complex tissues.
\end{abstract}

Keywords: fluorescence microscopy, fluorescent in situ hybridization, 3D genome architecture, topologically associating domains, transcription, Drosophila development, genome organization, chromosome conformation, chromatin. 


\section{Introduction}

Genomes are folded in a hierarchical organization that reflects and contribute to regulating transcription and other processes ${ }^{1}$. However, our current understanding of chromatin architecture and how it is related to transcriptional regulation remains limited. In the last decade, two strategies became mainstream to study chromatin folding: chromosome conformation capture (3C and derivatives) and microscopy-based methods. 3C-like methods are powerful as they provide genome-wide information with kilobase (kb) resolution, but have several limitations: (1) most often they rely on population averaging, (2) they retrieve relative frequencies of pairwise interactions, (3) they have relatively low detection efficiency in single cells ( $<10 \%$ of the total contacts), (4) they are unable to provide spatial information (within the cell or the organism/ tissue), and (5) they do not permit simultaneous measurement of transcription and chromosome structure ${ }^{2}$. Microscopy-based strategies on the other hand, employ fluorescence in situ hybridization (FISH) to target specific loci and can access their 3D position inside the nucleus, but until very recently were limited to the detection of a small number of genomic locations (typically 3-4). We and others have recently overcame several of these limitations to reconstruct chromatin architecture and detect transcriptional status at the same time in single-cells while retaining spatial information. This new technology, that we termed Hi-M (high-throughput, high-resolution, high-coverage microscopy-based technology, see below), addresses these shortcomings by employing high-throughput synthesis of short oligonucleotide (oligo) probes combined with RNA labeling and multiple rounds of hybridization in a sequential imaging scheme enabling the measurement of transcriptional state and the localization of tens of different genomic loci within intact Drosophila embryos ${ }^{3}$. Similar approaches have also been employed in concurrent work ${ }^{4-6}$.

\section{Principle of the method}

$\mathrm{Hi}-\mathrm{M}$ builds on recent innovations in FISH probe design based on high-throughput microarray oligos synthesis, namely Oligopaints ${ }^{7,8}$ and on the pioneering design of multiplexing schemes for detecting hundreds of RNA species by imaging ${ }^{9,10}$. A microarray library with thousands of oligonucleotides (oligopool) is bioinformatically designed and commercially synthesized to target tens of different genomic locations. Each genomic locus (typically spanning 2-10 kb) is targeted by a unique set of 20-70 tiled oligos. We will refer to the genomic regions covered by these unique set of oligos as 'barcodes'. Each oligo in a barcode contains three parts, a region of genomic homology, a barcode-specific readout sequence; and a priming region for PCR 80 amplification (see Experimental design section). Labeling involves four steps. First, the oligopool library is enzymatically amplified and purified. Second, embryos are collected and fixed. Third, embryos are labeled by an RNA hybridization and signal amplification step. Fourth, the oligopool is hybridized to genomic DNA. After labeling, samples are mounted onto a microfluidic chamber connected to a microfluidics pump system and mounted into an automated widefield fluorescence microscope. In an initial round, DAPI and RNA signals are acquired in multiple regions of interest (ROIs). Then, 
the imaging of each barcode requires: (1) labeling of the sample with barcode-specific, fluorescently-labeled readout oligonucleotides (readout probes); (2) removal of unbound readout oligos by washing; (3) acquisition of 3D, two-color images for all ROIs and (4) photobleaching. This process is repeated sequentially for each barcode. In all sequential rounds, a second, spectrally different, fluorescent oligo is present and used as the fiducial barcode for drift correction. Next, images are processed to: segment DNA masks, determine the transcriptional status of each cell, retrieve the 3D position of each barcode in every ROI with sub-pixel accuracy, and correct drift during acquisition and between cycles of hybridization. Finally, the 3D coordinates of each barcode detected in each cell are used to reconstruct Hi-M matrices containing mean pairwise distances and absolute contact probabilities.

\section{Applications of the method}

We have developed Hi-M to explore genome architecture and transcription in intact Drosophila embryos. However, Hi-M can be used in a large variety of model systems. For instance, adaptation to cultured cells should be straightforward. Cultured cells can be readily attached to the coverslip by standard procedures (e.g. by growing them in treated coverslips conductive of cell adhesion). In fact, cultured cells exhibit lower auto-fluorescence than organisms, thus the application of Hi-M should result in an increased barcode detection and localization precision. Hi-M could also be adapted to thick tissues and organoids by relying on cryo-sectioning ${ }^{11}$ or on optical-sectioning.

The RNA/DNA staining procedures described in this protocol are fully compatible with other imaging modalities, such as 3D Structured Imaging Microscopy (3D-SIM) or Stochastic optical reconstruction microscopy (STORM) ${ }^{4,5}$. The acquisition of super-resolution images is typically slower than for wide-field microscopy images, therefore limiting the throughput of a Hi-M acquisition. Thus, a compromise between resolution and throughput will have to be found depending on the problem under study.

115 In addition, most super-resolution microscopies are not well adapted to thick specimens, thus their use in Hi-M will be mainly limited to thin samples.

The flexibility afforded by Oligopaints in the design of probes would enable the adaptation of Hi-M to explore chromosome conformation at different length scales (e.g. chromosomal $^{12}$, compartment ${ }^{5}$ or TAD levels $\left.{ }^{3,6}\right)$. In the present protocol, barcodes contain $\sim 20-90$ primary oligos and cover 2-10 kb to produce diffraction-limited spots and ensure excellent signal-to-noise ratios (SNR, defined as the maximum intensity of a spot divided by the standard deviation of the background). Labeling of smaller genomic regions is possible but at the expense of reduced SNR levels (i.e. reduced localization precision).

\section{Limitations}

A current limitation of $\mathrm{Hi}-\mathrm{M}$ is the time required for the acquisition of an entire dataset: typically 2-3 days to image 50-70 barcodes in 30 fields of view (representing $\sim 50000$ cells for Drosophila embryos). Thus, typically a balance between experimental time and the number of barcodes imaged needs to be found. For instance, 70 barcodes could be used to image an extended genomic region (e.g. $3.5 \mathrm{Mb}$ ) at low 
resolution (50 kb between barcodes), or to image a single genomic locus (e.g. 150kb) at high resolution $(\sim 2 \mathrm{~kb})$.

A second limitation is the minimal number of primary probes per barcode. The values provided in this protocol (see Experimental Design section) ensure robust detection with high localization precision. A reduction in the number of primary probes could lead to decreased levels of detection and degraded localization precision. A possible future solution to this limitation may be to increase the number of imaging probes by encoding more readout probes per barcode (e.g. using SABER-FISH ${ }^{13}$ ), but ultimately this approach may limit the specificity of labeling.

A third limitation is the reduced efficiency of barcode detection, currently close to $60-70 \%$. Thus, a barcode is observed in only $\sim 6-7$ out of 10 nuclei. This entails a reduced number of cells containing all barcodes.

A fourth limitation arises from the high cost of fluorescently-labeled oligos $(\sim 500 \$$ each). As each barcode is detected by a specific fluorescently-labeled readout probe, the price of an experiment increases linearly with the number of barcodes. A new strategy that can considerably reduce the experimental cost has been recently described in two publications ${ }^{6,14}$. Instead of using a fluorescently labeled oligo for each barcode, a combination of two oligos is used: a non-fluorescent oligo specific for each barcode (bridge oligo) and a single fluorescent oligo common to all barcodes (imaging oligo). The bridge oligo contains 20 nucleotides (-nt) complementary to the barcode sequence, followed by a 10-nt "toehold" spacer sequence and a 20-nt sequence complementary to the imaging oligo ${ }^{15}$. With this design, the same fluorescently-labeled imaging oligo can be used to read all barcodes, with barcode specificity provided by the bridge oligo. Furthermore, this strategy can also be exploited to remove the fluorescence after each imaging cycle by the use of displacement oligos. Displacement oligos are complementary to the "toehold" and bridge probe sequences, therefore they displace the bridge probe from the barcode and in doing so they also remove the imaging probe.

A final limitation relies on the ability of Hi-M to detect several RNA species at once. The Hi-M protocol described here enables the simultaneous detection of chromosome conformation together with a single RNA species. In future, additional RNA species could be labeled by using a sequential TSA reaction with alternative conjugation molecules (e.g. biotin) or by relying on oligonucleotide-derivatized antibodies. It is worth noting that TSA amplification is non-linear, therefore quantification of RNA levels requires proper calibration.

\section{Comparison with other methods}

Compared to traditional FISH, Hi-M has two main advantages: (1) it uses oligo probes, that provide design flexibility and higher efficiency of labeling compared to double stranded BAC or amplicon-based probes ${ }^{16,17}$, and (2) it employs a multiplexed approach that does not rely on the use of spectrally different fluorophores (limited to 2-4 in most applications). The overall strategy of Hi-M is conceptually similar to recent work employing sequential imaging schemes and oligopaint labeling ${ }^{4-6,18}$. The main differences with these studies are: (1) Hi-M enables simultaneous detection of RNA status and chromosome organization without sample unmounting and probe 
re-hybridization. Other approaches also enable RNA/DNA detection, but require the hybridization and imaging of RNA probes, unmounting of the sample followed by degradation of RNA, hybridization of DNA probes, and then remounting and imaging of the same cryo-sectioned samples ${ }^{6}$; (2) Hi-M allows, in contrast with other studies ${ }^{4-6}$, for the imaging of entire, intact organisms.

Multiplexing has also been recently achieved in the single-cell imaging of multiple RNA species ${ }^{10,11,19,20}$. These studies used combinatorial schemes to target $\sim 140^{10,11}$ to $\sim 10,000$ genes $^{19,20}$ using only $\sim 20$ hybridization cycles. RNA is typically present in many copies per cell and these copies are spatially well separated, making it possible to decode species using combinatorial approaches. Currently, the use of combinatorial approaches to label DNA are limited by the spatial overlap of barcodes, 190 the small number of DNA molecules detected (typically 1-4 depending on ploidy), and by the reduced efficiency of detection ( $60 \%$, see above). Excitingly, combinatorial approaches based on other principles ${ }^{14}$ may be usable in the near future to considerably increase the number of detected barcodes without a linear increase in the number of hybridization cycles.

$\mathrm{Hi}-\mathrm{M}$ and similar approaches based on FISH are carried out in fixed samples, thus they cannot provide dynamic information. Live imaging of single genomic loci has been achieved using a catalytically inactive Cas nuclease that is targeted to a loci by a small guide RNA (sgRNA) (for a review see ${ }^{21}$ ). Typically CRISPR-based imaging records the position of two genomic loci, although targeting up to 6 genomic loci has been achieved for repetitive sequences ${ }^{22}$. Imaging non-repetitive sequences has been proven challenging due to the complexity of simultaneously co-expressing multiple sgRNA species in one cell. Furthermore, off-target binding and background fluorescence can further limit the application of current CRISPR-based imaging methods. More recently, a radically different approach successfully followed the 3D position of a single gene in real time while simultaneously monitoring mRNA synthesis in the same cell ${ }^{23,24}$ by combining stem-loop-based labeling (MS2 and/or PP7 $7^{25-27}$ ) and the ParS/ParB system ${ }^{28}$. This approach was used to study the position of a genomic locus and a transcription spot at the same time in living Drosophila embryos ${ }^{24}$. This approach requires genetic manipulation to introduce ectopic sequences, and is limited at present to a maximum of two colors (typically a transcript and a genomic locus).

\section{Experimental design}

The Hi-M protocol presented here (Fig. 1) consists in the design and 215 amplification of Oligopaint probes (steps 1-39 and Fig. 2), collection and fixation of Drosophila embryos (steps 40-50), RNA and DNA labeling of embryos (steps 51-92), sample mounting (steps 93-100 and Fig. 3), sequential imaging of multiple genomic locations (steps 101-116 and Figs. 4-6), and image processing and analysis (steps 117-149 and Fig. 7-8) in order to reveal chromatin organization and its relationship with the transcriptional status of single nuclei (Fig. 9).

Oligopaint probes. The method is based on massive oligonucleotide synthesis to design probes targeting the genomic locations of interest to perform a FISH-based labeling approach ${ }^{29}$. This protocol describes how to design a library and amplify 

region of genomic homology composed of 42-nt complementary to the target locus, (2) a readout region composed of 32-nt complementary to a readout oligo bearing a fluorophore, and (3) two flanking 20-nt regions containing primers for the PCR amplification of the whole Oligopaint library. With this design, it is possible to include 2 readout sequences per primary oligo, in the 5'- and 3'- ends of the genomic homology region.

The design pipeline implemented in the current protocol is based on a previous development by Beliveau et al. $^{8}$ and requires the user to input the genomic region of interest and the number of probes per barcode or, alternatively, the genomic size per 235 barcode (Fig. 2a). The unique sequences were mined using OligoArray ${ }^{30}$ and are available online for a variety of species (Oligopaint website, https://oligopaints.hms.harvard.edu/). An alternative for the design of oligopaint primary probes, although limited to the human genome, is the use of the web interface (http://ifish4u.org) that allows for the selection of specific sets of oligos in a 240 user-friendly environment including $\sim 400$ validated probes ${ }^{31}$. Of note, a recent development, OligoMiner ${ }^{32}$, relieve the use of online databases as it is capable of discovering thousands of oligo probes in minutes, tailoring the design of each probe set to the experimental question at hand.

A minimal number of primary oligos per barcode is needed for a high enough SNR to detect barcodes with high localization precision. Currently, we use a minimum of 40 primary oligos/barcode (i.e. 80 fluorophores per barcode). This number is comparable to the 48 fluorophores used typically for single-molecule RNA FISH ${ }^{33}$. Given an average of 12 unique primary oligos per kb in Drosophila ${ }^{32}$, a probe can be as short as $\sim 3 \mathrm{~kb}$. In the human genome, the average number of primary oligos $/ \mathrm{kb}$ is 250 considerably lower, thus we would recommend using a probeset spanning $\sim 5 \mathrm{~kb}$ to ensure robust detection is most systems and conditions. Recently, a different oligo dataset has been mined with a higher density of probes $/ \mathrm{kb}^{31}$., possibly enabling for a reduction in the genomic size of the barcode. The fiducial barcode requires additional considerations, as it will need to be repeatedly imaged in each cycle of hybridization 255 (i.e. it will suffer more from photobleaching than standard barcodes). Thus, we recommend using a higher number of primary oligos for the fiducial barcode (e.g. 200 oligos spanning $\sim 20 \mathrm{~kb}$ ). Currently, we fit the position of the fiducial barcode by using a 3D Gaussian function, as the image of this barcode is a diffraction-limited spot. It is important to realize that if the genomic region occupied by the fiducial barcode 260 becomes too large, its image in the camera will not be diffraction-limited. This would need to be taken into consideration for the fitting of the position of this barcode by appropriate modifications in the analysis pipeline.

For library amplification, the protocol follows a strategy previously introduced by Moffitt and Zhuang for the detection of RNAs using combinatorial approaches ${ }^{34}$. In 265 short, library amplification consists of four steps: (1) the Oligopaint library is PCR-amplified using a reverse primer that adds the T7 promoter sequence, (2) the PCR product is converted to RNA via an in vitro transcription using T7 polymerase, (3) single-stranded DNA is generated via reverse transcription, and (4) the RNA template is degraded using alkaline hydrolysis (Fig. 2b). Quality and concentration are 
monitored during the different steps to ensure the success of the amplification and purification process (Fig.2 c-e).

Embryo collection and fixation. The protocol here does not deviate much from a previously published protocol ${ }^{35}$. Flies lay embryos on yeasted agar plates for $1.5 \mathrm{~h}$. Plates are incubated at $25{ }^{\circ} \mathrm{C}$ until embryos reach the desired developmental stage. Embryos are then collected, dechorionated by the use of bleach, thoroughly rinsed with water and immediately fixed by using formaldehyde and formaldehyde-saturated heptane. Fixative is then removed, methanol added and embryos vortexed. Embryos that sank to the bottom of the tube are devitellinized, which is critical to allow penetration of $\mathrm{FISH}$ probes into the sample. Devitellinized embryos are washed with methanol and stored at $-20{ }^{\circ} \mathrm{C}$ until further use.

RNA \& DNA FISH. The protocol has two main steps: RNA in situ hybridization followed by DNA Oligopaint FISH. To ensure RNA signal preservation after DNA FISH, tyramide signal amplification (TSA), adapted from a previous protocol ${ }^{36}$ is performed. The single-stranded digoxigenin-labeled RNA probe is obtained from an in vitro transcription reaction in the presence of digoxigenin haptenes as described elsewhere ${ }^{3,37}$. RNA probes are targeted with a specific antibody that is coupled to horseradish peroxidase (HRP). HRP then reacts with hydrogen peroxide creating tyramide free radicals from fluorophore-labeled tyramide, that will covalently bind to the vicinity of the RNA probe. It is possible to label a second RNA species by performing a sequential, second antibody/HRP incubation against a biotinylated probe. In any case, controls should be made to ensure specificity of the RNA probe/s. In our previous paper $^{3}$, we labeled the snail gene, that has a distinctive spatial expression pattern that 295 can be used to assert signal specificity. However, we did include a control sample without RNA probe to establish the expected background levels. In case the expression pattern of the target gene is homogenous (or unknown), an anti-sense probe can be used to verify that the sense probe is actually binding to the target RNA.

After the TSA reaction, DNA FISH is performed based on a previous method ${ }^{38}$ that we have optimized for Oligopaint hybridization.

Embryo attachment. Firm attachment of embryos to the flow chamber coverslip is essential to resist the pressure from non-continuous flow rates during a 2-3 day experiment. To this end, embryos are deposited and oriented on an agarose pad and then transferred to a glass coverslip coated previously with poly-L-lysine. The microfluidics chamber is then assembled and the system filled with liquid. The complete procedure is shown in Fig. 3.

For a different type of sample, tests should be performed to assure stable attachment. This should not be a problem if adherent cells are used. A control with a 310 labeled sample (e.g. using fiducial markers), imaged before and after a certain period of time ( $\sim 30 \mathrm{~min})$ of continuous flow and at the beginning and at the end of a full experiment should be performed to assess sample stability and stage drift. The software analysis pipeline corrects for stage drift (see Image analysis section), but if the sample become loose or detaches during the experiment, drift correction would not 315 be possible. 
Image acquisition. Hi-M requires three acquisition steps. The pre-sequential step involves the acquisition of 3D bright-field, and multi-color fluorescence images for each ROI. The channels in the pre-sequential step are as follows: [channel 1] 3D image for DNA masks (DAPI-stained nuclei, excited using the $405 \mathrm{~nm}$ laser line); [channel 2] 3D image for RNA (RNA-stained embryos excited using the 488 laser line); [channel 3] 3D image of the fiducial barcode used for image registration (obtained by using the 561 $\mathrm{nm}$ laser line).

The sequential imaging acquisition step involves sequential imaging of barcodes. For each cycle of hybridization (see below) a 3D, two-color fluorescence image is acquired: [channel 1] 3D image of the fiducial barcode (excitation using the $561 \mathrm{~nm}$ laser line); [channel 2] 3D image of the $N$-th barcode (acquired using the 641 $\mathrm{nm}$ laser line). Thus, for $N$ cycles of hybridization and $k$ ROls one obtains $k(2 N+4)$ three-dimensional images. In a typical experiment with 10 embryos ( $\sim 30$ ROIs) and 22 barcodes, one needs to analyze a total of 1440 3D images. In our current implementation, the acquisition time for 22 barcodes and $\sim 30$ ROls (i.e. 7-9 embryos) is around $24 \mathrm{~h}$. This time scales linearly with the total number of barcodes and ROIs. Drosophila embryos in nuclear cycle 14 have $\sim 6,000$ nuclei, thus $\sim 25,000$ nuclei can be retrieved in a single experiment.

335 Each cycle of hybridization involves the following steps: (1) injecting a solution containing the fluorescent readout oligo that will hybridize to the complementary sequence of the primary oligos of a barcode, (2) washing non-specifically bound or unbound readout oligos with a formamide-containing solution, (3) injecting an imaging solution including an oxygen scavenger enzymatic reagent to prevent photobleaching during acquisition, (4) stopping flow and perform the sequential imaging step described above for all desired ROIs, (5) bleaching barcodes (see below).

The bleaching step can be achieved by different means: (1) light-induced photobleaching using a high-power laser. The implementation of this option is straightforward but the time required for photo-bleaching all ROls scales linearly with the number of acquired ROIs; (2) chemical bleaching. This option requires the fluorescent molecule in the readout oligo to be attached via a disulfide linkage cleavable by the use of a mild reducing agent such as Tris(2-carboxyethyl)phosphine $(\text { TCEP })^{39}$. The advantage of this option is that all fluorophores are removed at once in a single step, making the bleaching time independent of the number of acquired ROIs.

350 We note that if chemical photobleaching is employed, the fluorophore in the fiducial barcode needs to be resistant to the reducing agent (i.e. do not use a disulfide linkage).

In the final acquisition step, a 3D bright field image for each ROI is acquired for a second time. This image is used later to verify that embryos did not detach during acquisition (see Controls below).

Image analysis. The first image analysis step involves the deconvolution of images to remove out-of-plane light to increase the SNR and contrast. We perform this operation using Huygens (SVI, Nederlands).

The second step involves the comparison of bright-field images of embryos before and after sequential imaging. Embryos displaying any apparent movement or morphological distortion are discarded from further analysis. 
Next, a custom-made code in MATLAB is used to perform the following image analysis steps after deconvolution (Figs. 7-8). The workflow starts with the segmentation of nuclei from pre-sequential images using a graphical user interface 365 (GUI). A number of parameters can be pre-tuned (threshold, z-range, etc.) (Fig. 8) and manually modified in the GUI. Next, the GUI loads the stack, extracts the usable z-range, corrects for inhomogeneous excitation, and flattens the image by maximum intensity projection. Next, a detection algorithm with tunable parameters (threshold, intensity range, etc.) segments nuclei by using adaptive thresholding and water 370 shedding. The masks are verified by the user and stored locally. Once parameters have been optimized and verified, all the ROls can be analyzed in batch.

A similar procedure is used to segment barcodes. This procedure involves loading the image, extracting the z-range, correcting for inhomogeneous excitation, and segmentation by local thresholding. An estimate of the 3D positions of barcodes is obtained from the center of gravity of the masks segmented in this step. These 3D coordinates are next refined by using a 3D gaussian fitting algorithm.

Finally, a registration step is performed by image cross-correlation of the fiducial barcodes. A correction vector is derived and applied for each barcode. Corrected 3D barcode coordinates and nuclei masks are then used to determine which 380 barcodes are associated with which nuclei. These data are used to calculate the mean absolute contact probabilities and normalized mean pairwise distances for each pair of barcodes (see heatmaps in Fig. 9).

Controls. During in situ hybridization, chromatin is denatured by heating in the presence of formamide to enable the binding of primary probes. First, to ensure that this step did not affect the labeling of RNA, it is necessary to compare RNA intensities and distributions before and after DNA hybridization.

Second, it is important to take steps to quantify the efficiency of hybridization of primary probes and the efficiency of binding of imaging probes. For this, it is useful to measure the distribution, the SNR, and the number of barcode spots per cell. These measurements should be performed for each barcode in several embryos. Barcode spots should appear dense and uniform across the field of view. In Drosophila, we typically observe that $\sim 60-70 \%$ of nuclei display barcode spots, reflecting the limited labeling efficiency. In these cells, $\sim 80 \%$ contain a single barcode, consistent with a high degree of homologous pairing ${ }^{40,41}$. In mammalian cells instead, two barcode spots should be detected in most labeled cells. The typical SNR in our experiments was 50-500 after deconvolution. A reduced SNR could indicate incomplete binding of primary or imager oligos.

Third, a bright-field image is acquired before and after the experiment to ensure that embryos did not move during the experiment. During the analysis phase, it is verified that embryos did not change morphology or position during the experiment. Small-scale changes in embryos may happen during acquisition, such as inhomogeneous expansions/contractions of a few hundred nanometers. To account for these, fiducial marks are used. This allows us to both correct for stage drift as well as to account for any inhomogeneous expansion or contraction.

Forth, Hi-M matrices should be generated from different regions of interest and for different embryos to test that the data is highly correlated (Pearson test on the Hi-M 
pairwise distances and contact probabilities). Finally, a consolidated Hi-M contact probability matrix is built and compared with existing $\mathrm{Hi}-\mathrm{C}$ datasets (Pearson test on contact probabilities). Additionally, it can be verified that TAD borders are located at the same genomic position for both datasets. When available, comparisons of Hi-M matrices with other sources of data (e.g. ChIP-seq, enhancer trapping) is also important to ensure the validity of the results.

415 Spatial resolution. In our approach we avoid chromatic shift by using a single channel to record all barcodes. By recording in two channels, the number of hybridization cycles can be reduced by half. However, chromatic aberrations needs to be properly corrected, as described elsewhere ${ }^{41}$. Stage drift is inherently present and also needs to be corrected using fiducial labels. The reported residual error of fiducial barcodes after drift correction is around $80 \pm 60 \mathrm{~nm}$ in $x y z^{3}$. Ultimately, this will limit the minimal distance that can be resolved between any two barcodes.

\section{Materials}

\section{Biological materials}

- Wild-type fruit flies (Bloomington Drosophila Stock Center) or the flies specified by the experiment.

\section{Reagents}

- 131-150 -nt Oligopool (CustomArray)

- KAPA Taq Kit with dNTPs (CliniSciences, cat. no. BK1003)

- HiScribe T7 High Yield RNA Synthesis Kit (New England Biolabs, cat. no. E2040S)

- Maxima H Minus Reverse transcriptase kit (Fisher Scientific, cat. no. 13243159)

- dNTP Set 100 mM Solution (Fisher Scientific, cat. no. 10083252)

- Rnasin Ribonuclease Inhibitors (Promega, cat. no. N2515)

- Oligo clean \& concentrator kit (Zymo, cat. no. D4060)

- DNA Clean \& Concentrator kit - $25 \mu$ g capacity (Zymo, cat. no. D4033)

- DNA Clean \& Concentrator kit - $100 \mu$ g capacity (Zymo, cat. no. D4029)

- SYBR Safe nucleic acid gel stain (Invitrogen, cat. no. S33102)

- RNA Loading Dye 2X (New England Biolabs, cat.no. B0363S)

- Low Range ssRNA Ladder (New England Biolabs, cat. no. N0364S)

- SYBR Gold Nucleic Acid Gel Stain (Fisher Scientific, cat. no. S11494)

- Agarose Standard DNA Grade (Euromedex, cat. no. D5-E)

- GeneRuler 100 bp DNA Ladder (Fisher Scientific, cat. no. SM0243)

- Ammonium acetate 5 M (Fisher Scientific, cat. no. 10534645)

- Glycogen 5 mg/mL (Ambion, cat. no. AM9510)

- TEMED (Thermo Scientific, cat. no. 17919)

- Ammonium Persulfate (APS) (Fisher Scientific, cat. no. 17874) 
- Acrylamide/Bis-Acrylamide 19:1, 40\% Solution (Fisher Scientific, cat. no. BP1406-01)

- Cetyl PEG/PPG-10/1 dimethicone (ABIL EM-90, Evonik)

- Diethyl ether (Sigma-Aldrich, cat. no. 296082)

- Ethyl acetate (Sigma-Aldrich, cat. no. 270989)

- Mineral oil (500 mL; Sigma-Aldrich, cat. no. M5904)

- Triton X-100 (250 mL; Sigma-Aldrich, cat. no. T8787)

- Tween-20 (500 mL; Sigma-Aldrich, cat. no. P2287)

- CHAPS (Sigma, cat. no. 226947)

- Dulbecco's phosphate-buffered saline (PBS) (Gibco, cat. no. 14190169)

- Poly-L-lysine solution (Sigma-Aldrich, cat. no. P8920)

- 20X Saline-sodium citrate buffer (SSC) containing $3 \mathrm{M} \mathrm{NaCl}$ in $0.3 \mathrm{M}$ sodium citrate (Thermo Fisher Scientific, cat. no. AM 9770)

- Tris Base, BM grade (Euromedex, cat. no. 200923-A)

- Sodium chloride (99,5\%) (Euromedex, cat. no. 1112-A)

- Sodium dihydrogen phosphate, dihydrate (Euromedex, cat. no. T879)

- Dry fine yeast (Lab Scientific, cat. no. FLY-8040-20F)

- Clorox Ultra Germicidal Liquid Bleach (Fisher Scientific,cat. no. 50371500)

- Heptane (Fisher Chemical, cat. no. O3008-4)

- 32\% Formaldehyde Solution (w/v), Methanol-free (Electron Microscopy Sciences, cat. no. 15714)

! CAUTION Paraformaldehyde is a toxic cross-linking agent. Wear protective gloves and handle it under the fume hood. Discard according to the relevant environmental health and safety instructions.

CRITICAL: The use of methanol-free paraformaldehyde to fix embryos can greatly reduce autofluorescence.

- 37 \% Formaldehyde solution (w/v) (Sigma-Aldrich, cat. no. 47608)

- Methanol (Fisher Chemical, cat. no. A412-4)

- Acetone (Merck, cat. no. 1000122500)

- Deionized formamide (100 ml; Amresco, cat. no. 0606)

! CAUTION Formamide is toxic and should be handled with protective gloves under a fume hood and discarded according to the relevant environmental health and safety instructions.

- $30 \%(w / w)$ hydrogen peroxide solution (Sigma-Aldrich, cat. no. H1009)

CRITICAL: The stabilizer included in this reagent warrants a long shelf time.

- Alexa Fluor 488 Tyramide Reagent (Invitrogen, cat. no. B40953)

- Tris(2-carboxyethyl)phosphine hydrochloride (TCEP; Sigma-Aldrich, cat. no. 646547)

- Anti-Digoxigenin-POD, Fab fragments (Roche, cat. no. 11207733910, RRID:AB_514500)

- Blocking reagent (Sigma-Aldrich, cat. no. 11096176001) CRITICAL: Commercial blocking reagent warrants reproducibility.

- RNase A (Sigma-Aldrich, cat. no. R6513)

- Dextran sulfate (Sigma-Aldrich, cat. no. D8906)

- Salmon sperm DNA (Ambion, cat. no. AM9680)

- Heparin (Sigma-Aldrich, cat. no. H4784) 
- $\quad$ BSA (Roche, cat. no. 10711454001)

- 4',6-Diamidine-2'-phenylindole dihydrochloride (DAP;; Roche, cat. no. 10236276001)

- Glucose oxidase (Sigma-Aldrich, cat. no. G2133)

- Catalase (Sigma-Aldrich, cat. no. C30)

- $\mathrm{D}(+)$ Glucose anhydrous (Euromedex, cat. no. UG3050)

- Alexa-647 readout probes (IDT DNA). Sequences can be found in Supplementary Table 1 and are complementary to the readout sequences.

- Rhodamine-labeled DNA oligo:

CATTGCCGTATGGGCTAGGATGACCTGGCTCG/3RhodRd-XN/ (IDT DNA)

510

\section{Equipment}

- PCR Machine (T100 Thermal cycler, Bio-Rad)

- Positive displacement micropipette Gilson M250 (Fisher Scientific, cat. no. F148505)

- 2 mL 11-mm Glass vial (VWR, cat. no. 66009-822)

- Magnetic stirring bar (BelArt, cat. no. 371191083)

- Magnetic stirrer (10 mm)

- NanoDrop spectrophotometer (Thermo Scientific, model no. ND-1000UV/Vis)

- Vortex, standard mini vortex (VWR )

- Falcon 15-mL Conical Centrifuge Tubes (Fisher Scientific, cat. no. 14-959-53A)

- Falcon 50-mL Conical Centrifuge Tubes (Fisher Scientific, cat. no. 14-959-49A)

- Tabletop centrifuge (Eppendorf, cat. no. 5424)

- Syringe $30 \mathrm{~mL}$ (Terumo, cat. no. SS-30S)

525 - Syringe $20 \mathrm{~mL}$ (Terumo, cat. no. SS-20S2)

- Embryo collection cage (8.75 cm × $14.8 \mathrm{~cm}$; Flystuff.com, cat. no. 59-101)

- Nylon Filter (BD Falcon, cat. no. 352350)

- Water bath Grant Instruments JBN5 (Fisher Scientific, cat. no. 15177015).

- Thermomixer-AccuTherm Microtube Shaking Incubator (Labnet, cat. no. I-4001-HCS)

- Gas burner

- Disposable scalpel (Swann-Morton, cat. no. 0516)

- Plastic petri dishes (Greiner Bio-One; $60 \mathrm{~mm}$ diameter petri dish, cat. no.628163)

535 - Disposable glass Pasteur pipette (VWR, cat. no. 612-1702)

- Glass vial for embryo collection (DWK Life Sciences, cat. no. 986562)

- Rotating wheel

- Wide-field epifluorescence microscope (see Reagent setup)

- Microscope coverslips (Bioptechs Inc., cat. no. 40-1313-0319)

- Microfluidics FCS2 chamber (Bioptechs Inc., cat. no. 03060319-2-NH)

- MFCS-EZ negative pressure pump (Fluigent, cat. no. EZ-80345001)

- Flow unit L (Fluigent, ref. FLU_L_D)

- Online degassing unit (HPLC DegaSi Plus, Cluzeau Info Labo, cat. no. 00036352A) 
- HVXM8-5 injection valve and controller (Hamilton, cat. no. 36766 \& 36798)

- MATLAB Release 2017b (Mathworks)

- Huygens deconvolution software (Scientific Volume Imaging, https://svi.nl//HuygensSoftware)

- A server running on Linux with 32 CPU processors, two GeForce GTX 1080Ti GPU cards, and 128GB of RAM.

\section{Reagent setup}

PCR Oil phase The mix final concentration is $95.95 \%$ mineral oil:4\% ABIL EM-90:0.05\% Triton X-100 oil phase $(\mathrm{v} / \mathrm{v} / \mathrm{v})$. If available, with the use of a positive displacement pipette it is possible to directly pipette $2 \mathrm{~mL}$ of ABIL EM90, $65 \mu \mathrm{L}$ of Triton X-100 and $47.975 \mathrm{~mL}$ of mineral oil to a $50-\mathrm{mL}$ Falcon tube. Add the mineral oil in two steps, vortexing in between them. If positive displacement pipette is not available, volume can be accurately determined by weighing. To prepare $50 \mathrm{~mL}$ of PCR oil phase, weigh $20.3 \mathrm{~g}$ of mineral oil (around $24 \mathrm{~mL}$ ) directly into a $50-\mathrm{mL}$ Falcon tube, add $2 \mathrm{~mL}$ of ABIL EM90 and $65 \mu \mathrm{L}$ of Triton X-100, vortex thoroughly and leave it rest for $5 \mathrm{~min}$. Then add $20 \mathrm{~g}$ of mineral oil and homogenize by inversion of the tube. Make $20 \mathrm{~mL}$ aliquots of PCR Oil phase and store indefinitely at $4{ }^{\circ} \mathrm{C}$.

$1 \mathrm{M} \mathrm{NaOH}$ solution Weigh $2 \mathrm{~g}$ of $\mathrm{NaOH}$ and mix it with $30 \mathrm{~mL} \mathrm{ddH_{2 }} \mathrm{O}$ in a $50-\mathrm{mL}$ 565 Falcon tube and dissolve. Complete to $50 \mathrm{~mL}$ and pass it through a $0.22 \mu \mathrm{m}$ filter. The solution can be stored at room temperature $\left(R T, \sim 23^{\circ} \mathrm{C}\right)$ for several months.

$0.5 \mathrm{M}$ EDTA solution To prepare $200 \mathrm{~mL}$, weigh $37.23 \mathrm{~g}$ of EDTA and mix it with 150 $\mathrm{mL}$ of $\mathrm{ddH}_{2} \mathrm{O}$ in a glass beaker. Add a magnetic stirring bar and stir while adjusting to pH 8 with $\mathrm{NaOH} 10 \mathrm{M}$. Add $\mathrm{dd}_{2} \mathrm{O}$ up to $200 \mathrm{~mL}$. Filter solution with a $0.22 \mu \mathrm{m}$ filter.

570 The solution can be stored at $4{ }^{\circ} \mathrm{C}$ for several months.

CRITICAL: EDTA will not dissolve until pH approaches to 8 . Verify the final solution as $\mathrm{pH}$ may decrease when EDTA is dissolved.

Water-saturated diethyl ether Mix $3 \mathrm{~mL}$ of diethyl ether with $3 \mathrm{~mL}$ of $\mathrm{ddH}_{2} \mathrm{O}$ and vortex for $30 \mathrm{sec}$. Allow the mixture to settle and use the organic upper phase. Prepare 575 freshly.

Water-saturated ethyl acetate Mix $2 \mathrm{~mL}$ of ethyl acetate with $2 \mathrm{~mL}$ of $\mathrm{ddH}_{2} \mathrm{O}$ and vortex for $30 \mathrm{sec}$. Allow the mixture to settle and use the organic upper phase. Prepare freshly.

10\% Tween 20 (v/v) solution Mix $50 \mu \mathrm{L}$ of Tween 20 with $450 \mu \mathrm{L}$ of $\mathrm{ddH}_{2} \mathrm{O}$ and vortex until the solution becomes homogeneous. Store at $4{ }^{\circ} \mathrm{C}$ for up to two weeks.

PBS-Tween 20 (PBT) solution Combine $49.5 \mathrm{~mL}$ of PBS with $500 \mu \mathrm{L}$ of $10 \%$ Tween 20 (v/v). CRITICAL: Prepare freshly.

PBS-Triton X-100 (PBS-Tr) solution Add $50 \mu \mathrm{L}$ of Triton X-100 to $10 \mathrm{~mL}$ of PBS and vortex until the solution becomes homogeneous. CRITICAL: Prepare freshly.

$5854 \%(\mathbf{w} / \mathbf{v})$ formaldehyde in PBS To prepare $8 \mathrm{~mL}$, mix $1 \mathrm{~mL}$ of 32\% formaldehyde $(w / v)$-methanol free with $7 \mathrm{~mL}$ of PBS. CRITICAL: Prepare freshly.

$\mathbf{5 \%}(\mathbf{w} / \mathrm{v})$ formaldehyde in PBT Mix $1.35 \mathrm{~mL}$ of $37 \%$ formaldehyde solution with $9 \mathrm{~mL}$ of PBT. CRITICAL: Prepare freshly.

TBE 10X solution Dissolve $60.55 \mathrm{~g}$ of Tris base, $30.9 \mathrm{~g}$ Boric acid and $3.7 \mathrm{~g}$ of EDTA. Adjust volume to $500 \mathrm{~mL}$ with $\mathrm{ddH}_{2} \mathrm{O}$. Store at RT indefinitely. 
Gel for denaturing urea polyacrylamide gel electrophoresis (Urea PAGE). Mix $6 \mathrm{~g}$ urea, $1.25 \mathrm{~mL}$ TBE $10 \mathrm{X}$ and $3.5 \mathrm{~mL}$ of $\mathrm{ddH}_{2} \mathrm{O}$. Heat the solution at $60{ }^{\circ} \mathrm{C}$ in a water bath until the urea is dissolved. Add $3.125 \mathrm{~mL}$ of acrylamide/bisacrylamide, $75 \mu \mathrm{L}$ of APS $10 \%$ and $15 \mu \mathrm{L}$ of TEMED. Cast the polyacrylamide gel in $0.75 \mathrm{~mm}$ thick spacers. 595 Prepare freshly.

RNA Hybridization solution (RHS) To prepare $250 \mathrm{~mL}$ of RHS, mix $125 \mathrm{~mL}$ of formamide, $62.5 \mathrm{~mL}$ of 20X SSC, $1.25 \mathrm{~mL}$ of $10 \mathrm{mg} / \mathrm{mL}$ heparin, $2.5 \mathrm{~mL} 10 \%$ Tween-20

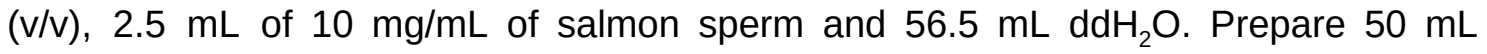
aliquots and stock at $-20^{\circ} \mathrm{C}$ for several months.

600 RNA probe preparation Put $2 \mu \mathrm{L}$ of RNA probe in $250 \mu \mathrm{L}$ of RHS, incubate at $85^{\circ} \mathrm{C}$ on a dry bath incubator for $2.5 \mathrm{~min}$. Then incubate on ice for at least two minutes before adding it to the embryos. CRITICAL: Freshly prepare the RNA probe, keeping it on ice no more than an hour before its use. Check the temperature of the dry bath to avoid probe degradation. Do not exceed 2.5 min incubation as high temperature might 605 degrade the probe.

Maleic acid buffer To make $200 \mathrm{~mL}$ of buffer, add $2.3 \mathrm{~g}$ of maleic acid, $1.7 \mathrm{~g}$ of NaCl, $1.2 \mathrm{~g}$ of $\mathrm{NaOH}$ and $100 \mathrm{~mL}$ of $\mathrm{ddH}_{2} \mathrm{O}$. Measure $\mathrm{pH}$ and adjust to $\mathrm{pH}=7.5$ with $5 \mathrm{M}$ $\mathrm{NaOH}$. Make up the volume to $200 \mathrm{~mL}$ with $\mathrm{dd}_{2} \mathrm{O}$ and filter. Solution can be stored at RT for up to six months.

610 5X blocking solution Combine $10 \mathrm{~g}$ of blocking reagent with $50 \mathrm{~mL}$ of maleic acid buffer, agitate and heat until complete dissolution. Complete to $100 \mathrm{~mL}$ with maleic acid buffer. Autoclave and make $10 \mathrm{~mL}$ aliquots. CRITICAL: 5X Blocking solution can be stored at $-20{ }^{\circ} \mathrm{C}$ for up to several months. Once defrozen, keep it on ice at all times.

1X blocking solution Prepare the solution by diluting to one fifth the $5 \mathrm{X}$ Blocking 615 solution with PBT.

CRITICAL: Freshly prepare solution and keep it on ice. Discard any remaining aliquot.

RNAse A solution Dissolve the $10 \mathrm{mg}$ vial in $1 \mathrm{~mL}$ of $\mathrm{dd}_{2} \mathrm{O}(100 \mathrm{X})$. Make small aliquots and store at $-20^{\circ} \mathrm{C}$ for up to a year.

$50 \%(w / v)$ Dextran sulfate To prepare the solution combine $25 \mathrm{~g}$ of dextran sulfate 620 with $40 \mathrm{~mL}$ of $\mathrm{ddH}_{2} \mathrm{O}$, heat to $37^{\circ} \mathrm{C}$ until it fully dissolves and then add $\mathrm{dd}_{2} \mathrm{O}$ to a final volume of $50 \mathrm{~mL}$. The solution can be stored at $4{ }^{\circ} \mathrm{C}$ for several months.

$100 \mathrm{mM} \mathrm{NaH}{ }_{2} \mathrm{PO}_{4} \mathrm{pH}=7$ To prepare $50 \mathrm{~mL}$ of this solution, mix $0.78 \mathrm{~g}$ of $\mathrm{NaH}_{2} \mathrm{PO}_{4}$ in $30 \mathrm{~mL}$ of $\mathrm{dd}_{2} \mathrm{O}$. Adjust to $\mathrm{pH}=7$, and complete with $\mathrm{ddH}_{2} \mathrm{O}$ to $50 \mathrm{~mL}$. Pass it through a $0.22 \mu \mathrm{m}$ filter. The solution can be stored at $4{ }^{\circ} \mathrm{C}$ for several months.

625 Pre-Hybridization Mixture (pHM) $50 \%$ formamide, $4 \times$ SSC, $100 \mathrm{mM} \mathrm{NaH} \mathrm{PO}_{4}$, $\mathrm{pH}=7,0.1 \%$ Tween 20. Prepare freshly.

DNA hybridization solution (DHS) Combine $5 \mathrm{~mL}$ of formamide, $2 \mathrm{~mL}$ of $50 \%(\mathrm{v} / \mathrm{v}$ ) Dextran sulfate, $1 \mathrm{~mL}$ of $20 X \mathrm{SSC}, 500 \mu \mathrm{L}$ of Salmon Sperm $(10 \mathrm{mg} / \mathrm{mL})$ and $1.5 \mathrm{~mL}$ of $\mathrm{ddH}_{2} \mathrm{O}$. Store at $-20^{\circ} \mathrm{C}$ for up to several months. Prewarm at $37^{\circ} \mathrm{C}$ before use.

$63050 \%(w / v)$ Glucose To prepare $40 \mathrm{~mL}$ of $50 \%(\mathrm{w} / \mathrm{v})$ glucose, combine $20 \mathrm{~g}$ of glucose with $30 \mathrm{mLddH_{2 }} \mathrm{O}$, heat to $60{ }^{\circ} \mathrm{C}$ until it dissolves and then add $d_{d d} \mathrm{H}_{2} \mathrm{O}$ to $40 \mathrm{~mL}$. The solution can be stored at RT for several months.

DAPI solution Prepare a $0.5 \mu \mathrm{g} / \mathrm{mL}$ DAPI solution in $1 \times$ PBS by diluting the stock solution. Store the solution with an aluminium fold at $4{ }^{\circ} \mathrm{C}$. The solution can be employed during several weeks. 
$1 \mathrm{M} \mathrm{NaCl}$ solution To prepare $50 \mathrm{~mL}$ of this solution, mix $2.92 \mathrm{~g}$ of NaCl with $30 \mathrm{~mL}$ of $\mathrm{ddH}_{2} \mathrm{O}$ in a $50-\mathrm{mL}$ Falcon tube and dissolve. Complete to $50 \mathrm{~mL}$ with $\mathrm{ddH}_{2} \mathrm{O}$ and pass it through a $0.22 \mu \mathrm{m}$ filter. The solution can be stored at RT for several months.

$1 \mathrm{M}$ Tris- $\mathrm{HCl} \mathbf{p H}=\mathbf{8}$ solution To prepare $50 \mathrm{~mL}$ of this solution, mix $6 \mathrm{~g}$ of Tris base with $30 \mathrm{~mL}$ of $\mathrm{dd}_{2} \mathrm{O}$. Using a $\mathrm{pH}$ meter, add slowly $\mathrm{HCl}$ using a glass pasteur pipette to reach the desired $\mathrm{pH}$. Complete to $50 \mathrm{~mL}$ with $\mathrm{dd}_{2} \mathrm{O}$, and pass it through a $0.22 \mu \mathrm{m}$ filter. The solution can be stored at RT for several months.

$55 \mathrm{mM} \mathrm{NaCl}$ in $11 \mathrm{mM}$ Tris- $\mathrm{HCl}$ pH=8 solution To prepare $50 \mathrm{~mL}$ of this solution, mix $2.75 \mathrm{~mL}$ of $1 \mathrm{M} \mathrm{NaCl}$ solution, $0.55 \mathrm{~mL}$ of $1 \mathrm{M}$ Tris- $\mathrm{HCl} \mathrm{pH=8}$ solution, and $46.7 \mathrm{~mL}$ of $645 \mathrm{ddH}_{2} \mathrm{O}$. Prepare freshly.

Gloxy solution To prepare $1 \mathrm{~mL}$ of Gloxy solution, mix $50 \mathrm{mg}$ Glucose oxidase, 100 $\mu \mathrm{L}$ catalase and $900 \mu \mathrm{L}$ of $55 \mathrm{mM} \mathrm{NaCl}$ in $11 \mathrm{mM}$ Tris- $\mathrm{HCl} \mathrm{pH}=8$. CRITICAL: Make 60 $\mu \mathrm{L}$ aliquots and store at $-20{ }^{\circ} \mathrm{C}$. Solution is stable for several months. Defrost on the day of the experiment and keep it on ice until use. If there is a precipitate, spin it down 650 and employ the supernatant. Once defrozen, the aliquot should be used within one week.

Hi-M wash buffer To prepare $100 \mathrm{~mL}$, combine $10 \mathrm{~mL}$ of $20 \mathrm{XSC}, 40 \mathrm{~mL}$ of formamide and make up to $100 \mathrm{~mL}$ with $\mathrm{ddH}_{2} \mathrm{O}$ (Final concentration of $40 \% \mathrm{v} / \mathrm{v}$ formamide). CRITICAL: Freshly prepare formamide containing solutions and pass them through a $0.22 \mu \mathrm{m}$ filter.

Hi-M acquisition solution To prepare $10 \mathrm{~mL}$ of solution, combine $1.1 \mathrm{~mL}$ of $50 \%$ (w/v) glucose with $9.9 \mathrm{~mL}$ of PBS and $110 \mu \mathrm{L}$ of Gloxy. CRITICAL: Add Gloxy solution just before using the solution and mix. Once the tubing is introduced, add a layer of mineral oil to prevent contact with oxygen from the ambient. Replace after 12-15 h.

660 Readout probe solution The final composition of this solution is $25 \mathrm{nM}$ of the corresponding readout oligo in $40 \%(\mathrm{v} / \mathrm{v})$ formamide 2X SSC. Readout oligos sequences can be found in Supplementary Table 1. CRITICAL: Prepare freshly and keep it protected from light.

Chemical bleaching solution To prepare $10 \mathrm{~mL}$ of chemical bleaching solution, mix 665 one 1-mL ampule of TCEP with $9 \mathrm{~mL}$ of 2X SSC. CRITICAL: Prepare the solution right before its use and discard any remaining solution.

Wide-field epifluorescence microscope A modular microscope system (RAMM, Applied Scientific Instrument) equipped with a 60x water-immersion objective (Plan-achromat NA=1.2, Nikon) and a sCMOS camera (Orca Flash 4.0v3, 670 Hamamatsu) is used for Hi-M imaging. With this objective/tube lens combination, we obtained a $108 \mathrm{~nm}$ pixel size, leading to a $\sim 220 \times 220 \mu \mathrm{m}$ field of view. Sample displacement and embryo selection are performed using a 2-axis translation stage (MS2000, Applied Scientific Instrumentation). Wide-field epifluorescence illumination is achieved using 405/488/561 and 641 nm lasers (OBIS-405/488/640 and Sapphire 561

675 - Coherent) combined with an acousto-optic tunable filter (AOTFnC-400.650, AA opto-electronics). To avoid the use of a mechanical filter-wheel, separation between excitation and emission light is done using a four-band dichroic mirror (zt405/488/561/640rpc-UF2, Chroma) combined with a four-band emission filter (ZET405/488/561/640m, Chroma). Finally, the objective lens is mounted on a 680 single-axis piezo-stage (Nano-F100, Mad City Labs Inc.), allowing for a nm-precision control of the objective axial position during z-scan and focus stabilization. 
A home-made focus stabilization system was used to compensate the axial drift in real-time. A $785 \mathrm{~nm}$ laser beam (OBIS-785, Coherent) is focused on the back-focal plane of the objective, reaching the coverslip/sample interface in near-TIRF illumination conditions. The position of the reflected beam is then measured on a position-sensitive detector (OBP-A-4H, Newport) and any variation in the objective-sample distance above $100 \mathrm{~nm}$ is automatically compensated by repositioning the objective lens.

$\mathrm{Hi}-\mathrm{M}$ sequential hybridization: Design for fluid handling circuits was implemented as described in Cardozo Gizzi et al ${ }^{3}$. The sample is mounted in a FCS2 chamber and flow is created using a negative pressure pump. An online flow-unit is used to continuously monitor flow-rate, allowing for a precise control of injected volumes as well as for maintaining a steady flow in the chamber. Buffers and probes are selected using a combination of three eight-way HVXM8-5 valves. Finally, an online degassing unit is inserted before the fluidic chamber to avoid air-bubble nucleation during $\mathrm{Hi}-\mathrm{M}$ 695 experiments.

User/microscope interface: Image acquisition, sample positioning and liquid handling are controlled by a custom-made software package developed in LabView 2015.

\section{Procedure}

\section{Design of Oligopaint libraries * Timing 4-5 $\mathrm{h}$}

1. Download Oligopaint scripts $^{7}$ and .bed files containing all primary oligos following the instructions in http://genetics.med.harvard.edu/oligopaints.

CRITICAL STEP: .bed files contain the sequences of oligos previously mined using OligoArray ${ }^{30}$ or OligoMiner ${ }^{32}$, covering the Drosophila non-repetitive genome.

2. Define genomic locations of interest (barcodes) and use grabRegion.py to select the oligos corresponding to each barcode. Register the number of oligos in each barcode.

CRITICAL STEP: Include also a fiducial barcode.

3. An output text file is created with a list of oligos for each barcode. Concatenate all output files using a Linux command line.

715 4. Create a unique text file with the readout sequences for all barcodes. It consists of a line for each barcode. In each line, add i) the 5' readout sequence, ii) the 3' readout sequence (repeat the previous sequence), iii) and the range of probes that compose the barcodes (i.e. 1-25, 26-50) based on the number of oligos in each barcode. Information i) to iii) must be separated with a Tab. Use the sequences from Supplementary Table 2.

CRITICAL STEP: The sequences must be given 5' to 3'.

5. Use order.py to add the readout sequences. It will require the full list of oligos from step 3 and the list of readout sequences to add from step 4.

6. Use order.py in interactive mode $(-i)$ with the output file from last step to add the sequence of the universal priming region. Use sequences from Supplementary Table 3. 
CRITICAL STEP: It is possible to embed multiple libraries within one oligopool by using different sets of universal primers.

7. Order the microarray from an oligopool synthesizer company.

CRITICAL STEP: Companies typically require two weeks to synthesize a custom-made oligopool.

\section{Amplification of Oligopaints * Timing 4-5 days}

8. Emulsion PCR. This step is performed to amplify the starting oligopool (which can be limiting) in a non-biased manner. Set up a PCR Master Mix for each library as indicated in Table 1 and keep it on ice until needed. Pre-chill a 2-mL $11 \mathrm{~mm}$ glass vial in the freezer, place it on the center of a controlled stir plate and then add a pre-cooled stirring bar to the vial. Transfer $600 \mu \mathrm{L}$ of PCR oil phase to the glass vial with a positive displacement pipette. Stir at $1000 \mathrm{rpm}$ for at least 1 minute. While the stirring bar is still spinning, add $100 \mu \mathrm{L}$ of PCR master mix in steps of $20 \mu \mathrm{L}$ increments using a P20 pipette (i.e. dispense 20 $\mu \mathrm{L} 5$ times). Stir at $1000 \mathrm{rpm}$ for 10 minutes, the emulsion should appear milky white and foamy. Transfer the emulsion to a PCR strip tube $(\sim 8 \times 75 \mu \mathrm{L})$ with a positive displacement pipette.

CRITICAL STEP: Forward primer is the $5^{\prime}=>3^{\prime}$ forward universal priming sequence whereas reverse primer is the reverse complement of the reverse universal priming sequence.

CRITICAL STEP: Emulsion preparation must be performed in a cold room at $4^{\circ} \mathrm{C}$. All the equipment must be put there in advance to cool it down before use. CRITICAL STEP: It would not be possible to transfer the whole emulsion volume to the PCR strip tube, quality over quantity here.

Table 1. Emulsion PCR master mix.

\begin{tabular}{|l|c|}
\hline Reagent & Quantity $(\mu \mathrm{L})$ \\
\hline ddH $_{2} \mathrm{O}$ & 79 \\
\hline 10X Taq buffer & 10 \\
\hline BSA $(10 \mu \mathrm{g} / \mu \mathrm{l})$ & 5 \\
\hline dNTPs $(10 \mathrm{mM})$ & 2 \\
\hline Forward primer $(200 \mu \mathrm{M})$ & 1 \\
\hline Reverse primer $(200 \mu \mathrm{M})$ & 1 \\
\hline $\begin{array}{l}\text { Kapa polymerase enzyme }(5 \\
\text { U/ } \mu \mathrm{L})\end{array}$ & 1 \\
\hline ssDNA library $(10-30 \mathrm{ng} / \mu \mathrm{l})$ & 1 \\
\hline
\end{tabular}


9. Perform the PCR using the following cycling conditions:

\begin{tabular}{llll}
\hline Cycle number & Denature & Anneal & Extend \\
\hline 1 & $95^{\circ} \mathrm{C}, 2 \mathrm{~min}$ & & \\
$2-31$ & $95^{\circ} \mathrm{C}, 15 \mathrm{sec}$ & $60^{\circ} \mathrm{C}, 15 \mathrm{sec}$ & $72^{\circ} \mathrm{C}, 20 \mathrm{sec}$ \\
32 & & & $72^{\circ} \mathrm{C}, 5 \mathrm{~min}$ \\
\hline
\end{tabular}

PAUSE POINT: PCR product can be stored at $4{ }^{\circ} \mathrm{C}$ for a few days.

10. Small scale emulsion PCR breaking. Pool the emulsion PCR reactions in a 1.5 $\mathrm{mL}$ microcentrifuge tube. Add $1 \mu \mathrm{L}$ of gel loading buffer to visualize the aqueous phase. Add $200 \mu \mathrm{L}$ of mineral oil and vortex for $30 \mathrm{sec}$. Centrifuge at maximum speed for $10 \mathrm{~min}$ and remove the upper organic phase.

11. Add $1 \mathrm{~mL}$ of water-saturated diethyl ether and vortex for $1 \mathrm{~min}$. Centrifuge at maximum speed for $1 \mathrm{~min}$ and remove the diethyl ether upper phase.

12. Add $1 \mathrm{~mL}$ of water-saturated ethyl acetate and vortex 1 for min. Centrifuge at maximum speed for $1 \mathrm{~min}$ and remove the ethyl acetate upper phase.

13. Repeat step 11. Evaporate the residual diethyl ether by incubating the tube at $37^{\circ} \mathrm{C}$ for 5 min with the cap open.

CRITICAL STEP: The final volume should be around $80 \mu \mathrm{L}$.

PAUSE POINT: PCR product can be stored at $4{ }^{\circ} \mathrm{C}$ for a few days.

14. Purify the DNA by using Zymo Oligo Clean \& Concentrator kit. Mix $80 \mu \mathrm{L}$ of DNA from the emulsion PCR breaking, $160 \mu \mathrm{L}$ of oligo binding buffer and 320 $\mu \mathrm{L}$ of ethanol. Homogenize the solution by pipetting up and down 10 times. Follow the manufacturer's instructions up to the DNA elution. Repeat elution with an extra $15 \mu \mathrm{L}$ of water and then add $20 \mu \mathrm{L}$ of water directly into the tube to obtain a final volume of $50 \mu \mathrm{L}$.

15. Quantify DNA concentration using a NanoDrop by directly taking $2 \mu \mathrm{L}$ of purified PCR product. Concentration should be between $20-40 \mathrm{ng} / \mu \mathrm{L}$.

16. Run a gel electrophoresis to check for a single band amplification with $200 \mathrm{ng}$ of PCR product in a $1.5 \%$ agarose gel with $0.01 \%$ SYBR Safe at $100 \mathrm{~V}$ for 45 $\min$.

PAUSE POINT: Purified products can be frozen at $-20^{\circ} \mathrm{C}$ for several months.

17. Perform the small scale limited-cycle PCR by setting up the following reaction mix for 8 tubes as indicated in Table 2. CRITICAL STEP: The limited number of cycles is done to find the cycle number where the PCR is still at is exponential phase (Fig. 2c). Perform this step before proceeding to the large-scale PCR.

CRITICAL STEP: The T7 promoter sequence (5'-TAATACGACTCACTATAGGGT-3') should be added to the reverse primer used for the emulsion PCR step to allow for the reverse transcription step. 
Table 2. Small scale limited-cycle PCR set-up.

\begin{tabular}{|l|l|}
\hline Product & Quantity per tube $(\mu \mathrm{L})$ \\
\hline Kapa buffer A & 5 \\
\hline dNTP $(100 \mathrm{mM})$ & 1 \\
\hline Forward primer (100 uM) & 0.5 \\
\hline Reverse primer $(100 \mathrm{uM})$ & 0.5 \\
\hline $\begin{array}{l}\text { Template emulsion PCR }(1 \mathrm{ng} / \mu \mathrm{L}) \\
\text { obtained in step 7.30 }\end{array}$ & 2.5 \\
\hline Kapa polymerase enzyme $(5 \mathrm{U} / \mu \mathrm{L})$ & 0.5 \\
\hline ddd ${ }_{2} \mathrm{O}$ & Make up to a final volume of $50 \mu \mathrm{L}$ \\
\hline
\end{tabular}

18. Run the following PCR program:

\begin{tabular}{llll}
\hline Cycle number & Denature & Anneal & Extend \\
\hline 1 & $95^{\circ} \mathrm{C}, 5 \mathrm{~min}$ & & \\
$2-15$ & $95^{\circ} \mathrm{C}, 30 \mathrm{sec}$ & $60^{\circ} \mathrm{C}, 45 \mathrm{sec}$ & $72{ }^{\circ} \mathrm{C}, 30 \mathrm{sec}$ \\
\hline
\end{tabular}

Pick up the corresponding tube after each of the cycles 8-15 just after the extension phase. To do so, quickly open the PCR machine, remove the corresponding tube, close the lid and resume program.

PAUSE POINT: PCR product can be left overnight $(\mathrm{ON})$ at $4^{\circ} \mathrm{C}$ or frozen for up to a month at $-20^{\circ} \mathrm{C}$.

19. Run $20 \mu \mathrm{L}$ of the PCR product in a $1.5 \%$ agarose gel with $0.01 \%$ SYBR Safe at $100 \mathrm{~V}$ for $45 \mathrm{~min}$. Find the cycle with a single band of the expected size and the maximum intensity (Fig. 2c).

20. Perform a large scale limited-cycle PCR by running a reaction mix for 16 tubes as indicated in Table 3. This step will generate a big quantity of Oligopaints.

CRITICAL STEP: The T7 promoter sequence should be added to the reverse primer to allow for the reverse transcription step.

815 Table 3. Large scale limited-cycle PCR mix.

\begin{tabular}{|l|l|}
\hline Product & Quantity $(\mu \mathrm{L})$ \\
\hline Kapa buffer A & 80 \\
\hline DNTP $(10 \mu \mathrm{M})$ & 16 \\
\hline
\end{tabular}




\begin{tabular}{|l|l|}
\hline Forward primer $(100 \mu \mathrm{M})$ & 8 \\
\hline Reverse primer $(100 \mu \mathrm{M})$ & 8 \\
\hline Kapa enzyme $(5 \mathrm{U} / \mu \mathrm{L})$ & 8 \\
\hline $\mathrm{ddH}_{2} \mathrm{O}$ & 600 \\
\hline Template Emulsion PCR $(1 \mathrm{ng} / \mu \mathrm{l})$ & 40 \\
\hline
\end{tabular}

21. Split the volume of the mix in Table 3 into $16 \times 50 \mu \mathrm{L}$ PCR tubes and run the PCR program from step 18 using the optimized number of cycles determined in step 19. Add a last extension cycle of $5 \mathrm{~min}$ at $72{ }^{\circ} \mathrm{C}$.

PAUSE POINT: PCR product can be safely stored for months at $-20^{\circ} \mathrm{C}$.

22. Run $20 \mu \mathrm{L}$ of the PCR product in an agarose gel as in step 16 to check that the PCR was successful.

? TROUBLESHOOTING

23. Collect the $50 \mu \mathrm{L}$-aliquots from the previous step in a $15 \mathrm{~mL}$ falcon tube and proceed to DNA column purification according to the manufacturer's instructions.

CRITICAL STEP: Use Zymo DNA purification kit with $25 \mu \mathrm{g}$ capacity. Elute using $30 \mu \mathrm{L}$ of DNAse- and RNAse-free water.

24. Quantify product concentration with a NanoDrop using double-stranded DNA parameters. This typically requires a $1 / 10$ dilution of a $2 \mu \mathrm{L}$ aliquot of the purified product. Concentration should be between $30-50 \mathrm{ng} / \mu \mathrm{L}$.

25. Run the reminder of the $1 / 10$ stock dilution in a $1.5 \%$ agarose gel as in step 16 (Fig. 2d).

CRITICAL: Check for a single band of the expected size.

26. Perform in vitro transcription by setting up the reaction mix as indicated in Table 4.

CRITICAL STEP: This step is a high-yield reaction that further amplifies the template molecules as well as converts them into RNA. It is necessary to keep RNAse-free conditions at all times.

? TROUBLESHOOTING

Table 4. In vitro transcription solution mix.

\begin{tabular}{|l|l|}
\hline Product & Quantity $(\mu \mathrm{L})$ \\
\hline Purified PCR product & $6 \mu \mathrm{g}$ template DNA \\
\hline ATP $(100 \mathrm{mM})$ & 6 \\
\hline UTP $(100 \mathrm{mM})$ & 6 \\
\hline CTP $(100 \mathrm{mM})$ & 6 \\
\hline
\end{tabular}




\begin{tabular}{|l|l|}
\hline GTP $(100 \mathrm{mM})$ & 6 \\
\hline $10 \times$ T7 buffer & 6 \\
\hline Rnase inhibitor $(40 \mathrm{U} / \mu \mathrm{L})$ & 2.25 \\
\hline HiScribe T7 polymerase & 6 \\
\hline $\mathrm{ddH}_{2} \mathrm{O}$ & Make up to a final volume of $60 \mu \mathrm{L}$ \\
\hline
\end{tabular}

27. Split the volume from the in vitro transcription solution into $3 \times 20 \mu \mathrm{L}$ PCR tubes and incubate at $37^{\circ} \mathrm{C}$ for $12-16 \mathrm{~h}$ in a thermocycler.

PAUSE POINT: In vitro transcription product can frozen for months at $-80^{\circ} \mathrm{C}$.

28. Take $5 \mu \mathrm{L}$ and purify with a Zymo Oligo Clean \& Concentrator kit according to manufacturer's instructions, using $15 \mu \mathrm{L}$ of DNAse and RNAse-free water to elute purified product.

CRITICAL STEP: The purification is only performed with a small aliquot to control if the in vitro transcription was successful and to estimate the RNA concentration in the non-purified RNA solution. Use Zymo DNA purification kit with $10 \mu \mathrm{g}$ capacity.

29. Make a $1 / 10$ dilution to perform a quantification of the purified RNA on NanoDrop using RNA parameters. Concentration should be between 0.5-2 $\mu \mathrm{g} / \mu \mathrm{L}$.

CRITICAL STEP: The concentration obtained allows to estimate concentration in non-purified RNA. For example, a $2 \mu \mathrm{g} / \mu \mathrm{L}$ concentration in the purified RNA can be translated to an estimated concentration of $6 \mu \mathrm{g} / \mu \mathrm{L}$ in the non-purified RNA considering a factor 3 dilution (from a $5 \mu \mathrm{L}$ aliquot to a final volume of 15 $\mu \mathrm{L}$ ). The total yield of the in vitro transcription step should be around 150-450 $\mu \mathrm{g}$ from a single transcription step $(60 \mu \mathrm{L}$ in total).

30. Check for the RNA quality by Urea PAGE (Fig. 2e). Perform a pre-run for 30 min in $1 X$ TBE at $190 \mathrm{~V}$ to eliminate the excess of persulfate. When finished, wash the wells with the running buffer. Load $100 \mathrm{ng}$ of purified RNA per lane. Heat the samples at $95{ }^{\circ} \mathrm{C}$ for $5 \mathrm{~min}$ and put it immediately on ice for $2 \mathrm{~min}$. Perform the PAGE for $1 \mathrm{~h}$ at $190 \mathrm{~V}$. For gel staining, incubate protected from light for $20 \mathrm{~min}$ in $30 \mathrm{~mL}$ of TBE $1 X$ and $3 \mu \mathrm{L}$ of SyBR Gold.

31. Perform the reverse transcription reaction according to Maxima $\mathrm{H}$ Reverse Transcriptase kit by setting up the reaction mix indicated in Table 5.

CRITICAL STEP: In this step, the non-purified RNA from step 27 is directly used. RNA should always be kept in ice to prevent degradation.

CRITICAL STEP: Primer sequence is the same as for forward primer used in emulsion PCR or limited-cycle PCR.

Table 5. Reverse transcription mix.

\begin{tabular}{|l|l|}
\hline Product & Quantity $(\mu \mathrm{L})$ \\
\hline Non purified transcription product & $150 \mu \mathrm{g}$ \\
\hline
\end{tabular}




\begin{tabular}{|l|l|}
\hline dNTP mix 100mM & 12 \\
\hline Forward Primer $(100 \mu \mathrm{M})$ & 50 \\
\hline $5 X$ Maxima buffer & 240 \\
\hline RNAsin Plus $(40 \mathrm{U} / \mu \mathrm{L})$ & 30 \\
\hline Maxima H reverse transcriptase $(200 \mathrm{U} / \mu \mathrm{L})$ & 30 \\
\hline $\mathrm{ddH}_{2} \mathrm{O}$ & $\begin{array}{l}\text { Make up to a } \\
\text { final volume of } 1200 \mu \mathrm{L}\end{array}$ \\
\hline
\end{tabular}

32. Split the volume obtained in the previous step into two $1.5 \mathrm{~mL}$ tubes and incubate for $3 \mathrm{~h}$ at $50^{\circ} \mathrm{C}$ in a water bath.

PAUSE POINT: Reverse transcription product can frozen for months at $-20^{\circ} \mathrm{C}$.

33. Perform the RNA degradation by adding into each tube $300 \mu \mathrm{L}$ of $0.5 \mathrm{M}$ EDTA and $300 \mu \mathrm{L}$ of $1 \mathrm{M} \mathrm{NaOH}$ and incubating at $95^{\circ} \mathrm{C}$ for $15 \mathrm{~min}$ in a water bath.

CRITICAL STEP: This step allows to selectively degrade the RNA while keeping single stranded DNA.

34. Take a $10 \mu \mathrm{L}$ aliquot to control for DNA concentration and to perform a gel electrophoresis as in step 16.

35. DNA probe purification. Mix the 2 aliquots in a sterile $50-\mathrm{mL}$ Falcon tube. Add $4.8 \mathrm{~mL}$ of oligo binding buffer and $19.2 \mathrm{~mL}$ of ethanol. Homogenize and spread over two columns. Follow the manufacturer's instructions from this point on. CRITICAL STEP: Use the Zymo DNA purification kit with $100 \mu \mathrm{g}$ capacity.

36. Take a $10 \mu \mathrm{L}$ aliquot to measure DNA concentration and to perform a gel electrophoresis as in step 16.

37. Ethanol precipitation. Directly add to the $150 \mu \mathrm{L}$ DNA elution, $24 \mu \mathrm{L}$ of $5 \mathrm{M}$ ammonium acetate, $6 \mu \mathrm{L}$ of glycogen and $750 \mu \mathrm{L}$ of $100 \%(\mathrm{v} / \mathrm{v})$ ethanol at $-20^{\circ} \mathrm{C}$. Vortex and incubate $1 \mathrm{~h}$ at $-80^{\circ} \mathrm{C}$. Centrifuge at $13,000 \mathrm{G}$ for $1 \mathrm{~h}$ at $4^{\circ} \mathrm{C}$. Discard the supernatant and wash the pellet with $1 \mathrm{~mL}$ of ice-cold $70 \%$ ethanol $(\mathrm{v} / \mathrm{v})$. Centrifuge at $13,000 \mathrm{G}$ for $15 \mathrm{~min}$ at $4^{\circ} \mathrm{C}$. Discard the supernatant and add $20 \mu \mathrm{L}$ of DNase- and RNase-free water. Let the single stranded DNA (sSDNA) resuspend for $10 \mathrm{~min}$ at $37^{\circ} \mathrm{C}$. Keep on ice.

38. Quantify oligo concentration with a NanoDrop using ssDNA parameters.

CRITICAL: Total quantity of SSDNA should be in the order of 80-120 $\mu \mathrm{g}$.

39. Control the quality of SsDNA by Urea PAGE as in step 30 (Fig. 2e).

CRITICAL STEP: This step allows to verify RNA degradation and the efficacy of reverse transcription step.

PAUSE POINT: Probes can be stored at $-20^{\circ} \mathrm{C}$ for months.

\section{Embryo collection and fixation * Timing 2-3 $\mathrm{h}$}

40. Place $200-400$ flies with a 2:1 female/male ratio into an egg-collection cage mounted with an apple juice plate containing a dollop of yeast paste and 
prewarmed to $25^{\circ} \mathrm{C}$ (or the temperature required for the specific experiment). Perform an ON pre-laying step.

41. Replace the plate with a new one containing a dollop of yeast paste and prewarmed to $25^{\circ} \mathrm{C}$. Perform a laying step during $1.5 \mathrm{~h}$ at $25^{\circ} \mathrm{C}$.

42. Remove the plate, put the cover and incubate $1 \mathrm{~h}$ (or the time required to obtain embryos in the desired developmental stage) at $25^{\circ} \mathrm{C}$.

43. Rinse the plates with $\mathrm{dd}_{2} \mathrm{O}$ and carefully detach embryos using a brush. Filter the liquid using a nylon filter. Embryos will remain on it.

44. Prepare a six well plate with one well containing bleach at $2.6 \%$ active chlorine, and the other five containing water. Put the filter with the embryos in the bleach containing well and incubate for $5 \mathrm{~min}$.

45. Rinse sequentially the embryos by immersing the nylon filter into the water-containing wells. Dry them in between steps by pressing on a paper tissue. Place the embryos at the center of the filter.

925 46. Using a $1 \mathrm{~mL}$ pipet, add $5 \mathrm{~mL}$ of $4 \%(\mathrm{v} / \mathrm{v})$ formaldehyde in PBS to rinse the filter and displace embryos into a $20-\mathrm{mL}$ glass vial.

! CAUTION Formaldehyde is toxic and should be handled with protective gloves under a fume hood and discarded according to the relevant environmental and safety instructions.

930 47. Add $5 \mathrm{~mL}$ of heptane to the vial, close and vigorously shake it manually during $30 \mathrm{sec}$. You may cover the cap of the vial with parafilm to avoid leakage of the formaldehyde and heptane solution inside. Incubate the embryos during 20 minutes at RT.

48. Aspirate the lower aqueous phase on the bottom of the vial using a glass Pasteur pipet.

! CAUTION Formaldehyde is toxic and should be handled with protective gloves under a fume hood and discarded according to the relevant environmental and safety instructions.

49. Add $5 \mathrm{~mL}$ of methanol and vortex the glass vial during 15 seconds. Using a glass Pasteur pipet, transfer the embryos at the bottom of the glass vial to a 1.5 $\mathrm{mL}$ tube.

! CAUTION Methanol is toxic and highly volatile and should be handled with protective gloves under a fume hood and discarded according to the relevant environmental and safety instructions.

CRITICAL STEP: Glass pipet is used to avoid embryos attaching to the walls. Avoid using plastic tips.

50. Wash the embryos three times with $1 \mathrm{~mL}$ of methanol.

PAUSE POINT: Fixed embryos can be stored in methanol at $-20^{\circ} \mathrm{C}$ for months.

RNA in situ hybridization * Timing 2.5 days

CRITICAL: This procedure can be omitted if only DNA-labeled embryos are required.

51. Transfer $30 \mu \mathrm{L}$ of fixed embryos to a $1.5 \mathrm{~mL}$ tube.

CRITICAL STEP: Use a glass Pasteur pipette. 
52. Rinse the embryos with $1 \mathrm{~mL}$ of $100 \%(\mathrm{v} / \mathrm{v})$ methanol. Wash the embryos with 1 $\mathrm{mL}$ of a $1: 1$ mixture of $100 \%(\mathrm{v} / \mathrm{v})$ methanol and $100 \%(\mathrm{v} / \mathrm{v})$ ethanol and incubate for 5 min at RT in a rotating wheel.

53. Rinse the embryos twice with $1 \mathrm{~mL}$ of $100 \%(\mathrm{v} / \mathrm{v})$ ethanol. Wash the embryos with $1 \mathrm{~mL}$ of $100 \%(\mathrm{v} / \mathrm{v})$ ethanol and incubate for $5 \mathrm{~min}$ at RT in a rotating wheel.

54. Repeat previous step.

CRITICAL STEP: These steps remove impurities and reduce background.

55. Rinse the embryos twice with $1 \mathrm{~mL}$ of $100 \%(\mathrm{v} / \mathrm{v})$ methanol. Wash the embryos with $1 \mathrm{~mL}$ of $100 \%(\mathrm{v} / \mathrm{v})$ methanol and incubate for $5 \mathrm{~min}$ at RT in a rotating wheel.

56. Wash the embryos with $1 \mathrm{~mL}$ of a $1: 1$ mixture of $100 \%(\mathrm{v} / \mathrm{v})$ methanol/ $5 \%(\mathrm{v} / \mathrm{v})$ formaldehyde in PBT and incubate for $5 \mathrm{~min}$ at RT in a rotating wheel. Rinse the embryos with $1 \mathrm{~mL}$ of $5 \%(\mathrm{v} / \mathrm{v})$ formaldehyde in PBT.

! CAUTION Formaldehyde is toxic and should be handled with protective gloves under a fume hood and discarded according to the relevant environmental and safety instructions.

57. Fix the embryos with $1 \mathrm{~mL}$ of $5 \%(\mathrm{v} / \mathrm{v})$ formaldehyde in PBT for $25 \mathrm{~min}$ at $\mathrm{RT}$ in a rotating wheel.

CRITICAL STEP: Post-fixation assures RNA integrity.

58. Rinse the embryos twice with $1 \mathrm{~mL}$ of PBT. Wash the embryos four times with $1 \mathrm{~mL}$ of PBT and incubate for $15 \mathrm{~min}$ at RT in a rotating wheel.

PAUSE POINT: Once rehydrated, the embryos can be stored in PBT for several hours at RT or for several days at $4{ }^{\circ} \mathrm{C}$ before continuing to next step.

59. Permeabilize the embryos by incubating with PBS-Tr for $1 \mathrm{~h}$ at RT in a rotating wheel.

60. Rinse the embryos with $1 \mathrm{~mL}$ of PBT. Wash the embryos three times with $1 \mathrm{~mL}$ of PBT and incubate for $5 \mathrm{~min}$ at RT in a rotating wheel.

61. Wash the embryos with $1 \mathrm{~mL}$ of a 1:1 mixture of RHS/ PBT and incubate for 10 min at RT in a rotating wheel.

PAUSE POINT: It is possible to store the embryos in RHS at $-20^{\circ} \mathrm{C}$ for several weeks.

62. Incubate the embryos with $1 \mathrm{~mL}$ of prewarmed RHS in a Thermomixer at $800-900 \mathrm{rpm}$ at $55^{\circ} \mathrm{C}$ for $10 \mathrm{~min}$.

! CAUTION RHS contains formamide, that is toxic and should be handled with protective gloves under a fume hood and discarded according to the relevant environmental and safety instructions.

63. Change media with fresh RHS and incubate the embryos at $55{ }^{\circ} \mathrm{C}$ in a Thermomixer at 800-900 rpm for $45 \mathrm{~min}$.

CRITICAL STEP: Before changing media, allow the embryos to settle down to the bottom of the tube. Since RHS is highly viscous, this could take several minutes. It is possible to use Thermomixer at $300 \mathrm{rpm}$ to speed up the process.

64. Repeat previous step with an incubation time of $1 \mathrm{~h}$ and $15 \mathrm{~min}$.

65. Completely remove RHS and immediately add the $250 \mu \mathrm{L}$ of RNA probe (see Reagent setup for probe preparation). Incubate the embryos at $55{ }^{\circ} \mathrm{C} \mathrm{ON}$ in a Thermomixer at 800-900 rpm. 
CRITICAL STEP: Work fast to ensure embryos remain at $55^{\circ} \mathrm{C}$ when adding the probe directly from the ice.

66. Recuperate the used probe for two more utilizations by carefully aspirating the supernatant. Used probe can be stored at $-20{ }^{\circ} \mathrm{C}$ for up to several months. CRITICAL STEP: Allow the embryos to settle down to the bottom of the tube by stopping the thermomixer agitation for 3-5 $\mathrm{min}$.

67. Rinse the embryos twice with $1 \mathrm{~mL}$ of $\mathrm{RHS}$ prewarmed to $55^{\circ} \mathrm{C}$. Wash the embryos four times with $1 \mathrm{~mL}$ of prewarmed RHS in a Thermomixer at 800-900 rpm at $55^{\circ} \mathrm{C}$ for $30 \mathrm{~min}$.

1010 68. Wash the embryos with $1 \mathrm{~mL}$ of a 1:1 mixture of RHS/PBT and incubate for 10 min at RT in a rotating wheel.

69. Wash the embryos three times with $1 \mathrm{~mL}$ of PBT and incubate for 20 min at RT in a rotating wheel.

70. Perform a saturation step by incubating with $1 X$ blocking solution for $45 \mathrm{~min}$ at $\mathrm{RT}$ in a rotating wheel.

CRITICAL STEP: The use of the commercially available blocking solution greatly reduces unspecific binding of the antibody.

71. Remove $1 \mathrm{X}$ blocking solution and incubate the embryos with $1 \mathrm{~mL}$ of $1 \%$ hydrogen peroxide(v/v) in PBT for 30 min at RT in a rotating wheel.

CRITICAL STEP: The inactivation of endogenous peroxidases is required to avoid a high fluorescence background.

72. Wash the embryos two times with $1 \mathrm{~mL}$ of PBT and incubate for $5 \mathrm{~min}$ at RT in a rotating wheel.

73. Incubate the embryo with the anti-DIG antibody (1/500 dilution in $1 X$ blocking

74. Rinse the embryos twice with $1 \mathrm{~mL}$ of PBT. Wash the embryos five times with 1 $\mathrm{mL}$ of PBT and incubate for $12 \mathrm{~min}$ at RT in a rotating wheel.

75. Incubate the embryos with the tyramide solution $(5 \mu \mathrm{L}$ of Alexa 488-tyramide reagent in $500 \mu \mathrm{L}$ of $\mathrm{PBT}$ ) for 30 min at $\mathrm{RT}$ in a rotating wheel.

1030 CRITICAL STEP: Use an aluminium foil to protect embryos from the light.

76. Prepare a $1.5 \%$ hydrogen peroxide(v/v) solution. Directly add $4 \mu \mathrm{L}$ of the solution in the previous step to the embryos and incubate for $30 \mathrm{~min}$ at RT in a rotating wheel.

77. Rinse the embryos twice with $1 \mathrm{~mL}$ of PBT. Wash the embryos three times with $1 \mathrm{~mL}$ of PBT and incubate for $5 \mathrm{~min}$ at RT in a rotating wheel.

PAUSE POINT: RNA-labeled embryos can be stored for weeks at $4{ }^{\circ} \mathrm{C}$ before proceeding to DNA labeling or imaging.

\section{DNA In situ hybridization * Timing 1.5 days}

1040 78. Transfer $\sim 30 \mu \mathrm{L}$ of embryos from either step 50 or 77 to a $1.5 \mathrm{~mL}$ tube.

CRITICAL STEP: Use a glass Pasteur pipette to prevent embryos sticking to the pipette.

79. Rehydrate the fixed embryos by incubating them with $1 \mathrm{~mL}$ of the following solutions (1) $90 \%$ methanol, $10 \%$ PBT; (2) $70 \%$ methanol, $30 \%$ PBT; (3) 50 $\%$ methanol, $50 \%$ PBT; (4) $30 \%$ methanol, $70 \%$ PBT; (5) $100 \%$ PBT. Incubate 3-5 min at RT on a rotating wheel for each step. 
CRITICAL STEP: If the embryos are RNA-labeled, omit previous step.

80. Incubate the embryos with $1 \mathrm{~mL}$ of PBT, $100 \mu \mathrm{g} / \mathrm{mL}$ of RNAse for $2 \mathrm{~h}$ at RT or $\mathrm{ON}$ at $4{ }^{\circ} \mathrm{C}$ in a rotating wheel.

1050 81. Permeabilize the embryos by incubating them with PBS-Tr for $1 \mathrm{~h}$ at RT in a rotating wheel.

82. Transfer tissues into pHM by passing embryos through $1 \mathrm{~mL}$ of the following freshly made solutions: (1) $80 \%$ PBS-Tr, $20 \%$ pHM; (2) $50 \%$ PBS-Tr, $50 \%$ pHM; (3) $20 \%$ PBS-Tr, $80 \%$ pHM; (4) $100 \%$ pHM. Incubate 20 min at RT on a rotating wheel for each step.

CRITICAL STEP: Before exchanging solutions, allow the embryos to settle down 2-3 min.

83. Prepare primary DNA probe by adding $45-225$ pmol of Oligopaint probe to 25 $\mu \mathrm{L}$ of DHS. Keep the mix on ice. Denature primary DNA probe by incubating for $15 \mathrm{~min}$ at $80^{\circ} \mathrm{C}$ in the Thermomixer.

CRITICAL STEP: The amount of probe employed should be tested by quantifying the efficiency of labeling vs. increasing concentrations of DNA probe

84. Carefully remove the pHM solution from the embryos tube and add $1 \mathrm{~mL}$ of fresh pHM. Denature embryonic DNA by incubating for $15 \mathrm{~min}$ at $80{ }^{\circ} \mathrm{C}$ in a water bath.

85. Carefully remove the pHM solution from the embryos tube and add $30 \mu \mathrm{L}$ of the probes. Mix by gently flicking the tube with a finger. Carefully add $40 \mu \mathrm{L}$ of mineral oil. Change the water bath temperature to $37^{\circ} \mathrm{C}$ and incubate the embryos $\mathrm{ON}$ at $37^{\circ} \mathrm{C}$ in the water bath.

CRITICAL STEP: Mineral oil layer is added on top to prevent evaporation.

CRITICAL STEP: Allowing the embryos to slowly cool down from $80{ }^{\circ} \mathrm{C}$ to 37 ${ }^{\circ} \mathrm{C}$ in the water bath greatly increases efficiency of labeling.

86. Carefully remove as much mineral oil as possible from the tube with a P20 pipette.

CRITICAL STEP: Remaining oil dramatically affects embryo attachment to coverslips, as well as interfere with image acquisition.

87. Add $500 \mu \mathrm{l}$ of $50 \%$ formamide, $2 \times$ SSC, $0.3 \%$ CHAPS and remove supernatant.

1080 CRITICAL STEP: This helps to immediately remove the mineral oil after hybridization. If the quantity of remaining oil is too big, this step will not be enough to prevent posterior issues of attachment and image acquisition.

88. Perform post-hybridization washes by passing embryos through $1 \mathrm{~mL}$ of the following freshly made solutions : (1) $50 \%$ formamide, $2 \times$ SSC, $0.3 \%$ CHAPS; repeat this wash once; (2) $40 \%$ formamide, $2 \times$ SSC, $0.3 \%$ CHAPS; (3) $30 \%$ formamide, $70 \%$ PBT; (4) $20 \%$ formamide, $80 \%$ PBT; (5) $10 \%$ formamide, 90 \% PBT; (6) $100 \%$ PBT; (7) $100 \%$ PBS-Tr. Perform washes (1)-(4) 20 min at 37 ${ }^{\circ} \mathrm{C}$ in a thermomixer with agitation (800 to $900 \mathrm{rpm}$ ), perform washes (5)-(7) 20 min at RT on a rotating wheel.

1090 89. (Optional) Rinse the embryos with $1 \mathrm{~mL}$ of PBT. Crosslink primary library by incubating the embryos with $1 \mathrm{~mL}$ of $4 \%(\mathrm{w} / \mathrm{v})$ paraformaldehyde in PBT for 30 min at RT in a rotating wheel. 
CRITICAL: Although optional, in our hands crosslinking the primary library improved the labelling efficiency.

1095 90. Rinse the embryos with $1 \mathrm{~mL}$ of PBT. Incubate the embryos with Rhodamine-labeled readout probe in $1 \mathrm{~mL}$ hybridization buffer $(25 \mathrm{nM}$ readout probe, $2 X$ SSC, $40 \% \mathrm{v} / \mathrm{v}$ formamide) for $30 \mathrm{~min}$ at $\mathrm{RT}$ in a rotating wheel.

CRITICAL STEP: Rhodamine-labeled probe is used for the fiducial barcode, protect samples from light exposure.

1100 91. (Optional) Perform an additional crosslinking step as in step 89.

92. Rinse the embryos with $1 \mathrm{~mL}$ of PBT. Incubate the embryos with DAPI for 20 min at RT in a rotating wheel. Afterward, remove the DAPI and rinse the embryos three times with $1 \mathrm{~mL}$ of PBS.

CRITICAL: Detergent-containing PBT can prevent embryos from attaching to the coverslip.

PAUSE POINT: DNA-labeled embryos can be stored for weeks at $4{ }^{\circ} \mathrm{C}$ before proceeding to mounting and imaging.

\section{Attachment of embryos to microfluidic chamber * Timing $1 \mathbf{h}$}

1110 93. Wash a coverslip sequentially with acetone, ethanol and water and dry it with a soft flame. Put it into a $35 \mathrm{~mm}$ plastic dish.

CRITICAL: Heating excessively the coverslip with the flame may deform it and may affect imaging and sealing of the sample in the microfluidics chamber.

94. Add $1 \mathrm{~mL}$ of poly-L-lysine solution (1:10 dilution in $\mathrm{dd}_{2} \mathrm{O}$ ) to the coverslip and 1115 incubate for 20 min at RT. Steps for embryo attachment are shown in Fig. 3a. Afterward, rinse the coverslip with $\mathrm{dd}_{2} \mathrm{O}$.

95. Dry the coverslip with a paper tissue. Thoroughly dry the coverslip by using compressed air.

CRITICAL STEP: Embryos will not attach if coverslip is not completely dry.

1120 96. Cut a piece of agarose and put it under the binocular microscope. Transfer 20-30 embryos to the agarose pad.

CRITICAL STEP: Use a glass Pasteur pipette.

97. Align the embryos using metal tweezers and looking at the binocular microscope. It might be necessary to wait for a few minutes for excess of PBS

1125 to evaporate, which facilitates visualization and the displacement of embryos over the agarose pad.

CRITICAL STEP: Alignment will greatly facilitate finding the embryos in the microscope when defining ROls. Be gentle when touching/moving the embryos with the tweezers, otherwise embryos could break.

1130 98. Dry the embryos using a paper tissue to absorb surrounding liquid.

CRITICAL STEP: Embryos will not attach if there is an excess of liquid. If necessary, wait a few minutes for the liquid to evaporate.

99. Attach the embryos to a poly-L-lysine-coated coverslip by gently pressing coverslip against the agarose pad.

1135 CRITICAL STEP: Press gently for a few seconds to ensure attaching.

100. Put the coverslip in a $35 \mathrm{~mm}$ plastic dish with PBS until ready for chamber assembly

? TROUBLESHOOTING 
1140 Hi-M data acquisition * Timing $\sim 1-1.5 \mathrm{~h}$ per barcode

CRITICAL: Experiments are performed on a home-made wide-field epifluorescence microscope coupled to a microfluidics device.

101. Wash all the microfluidics tubing with $\mathrm{ddH}_{2} \mathrm{O}$ first and then with filtered $2 \mathrm{X}$ SCC.

1145 CRITICAL STEP: Microfluidics tubing should remain filled with $50 \%$ ethanol between experiments, which prevents bacterial growth and, at the same time, facilitates air bubble removal.

CRITICAL STEP: Check that pressure/flow rate is constant for all valves to discard clogging.

1150 102. Open the microfluidics chamber by unscrewing it. Carefully remove the glass coverslip from the chamber. Steps for chamber assembly are shown in Fig. 3b.

103. Remove the plastic spacer and dry it thoughtfully with a paper tissue.

CRITICAL STEP: Dry as much as possible the whole microfluidics chamber

104. Put back the dried spacer and mount the coverslip with the attached embryos

1155 105. Screw the chamber and mount it into the platine of the microscope.

106. Fill the chamber with $2 X$ SSC by slowly aspirating the buffer with a $10 \mathrm{~mL}$ syringe.

CRITICAL STEP: If the pressure exerted at this stage is to high, embryos risk to detach. At the time of the filling, keep the chamber upwards to prevent air retention.

\section{? TROUBLESHOOTING}

107. Connect all tubings with the corresponding solution and note the respective Hamilton valves numbers.

108. Put a small drop of oil onto the objective and make focus on the coverslip 1165 surface. Locate the embryos using brightfield imaging.

CRITICAL STEP: Check if embryos are properly attached. Embryos borders can be observed out of focus when embryos are detaching.

? TROUBLESHOOTING

109. Select the ROIs by checking the DAPI stained nuclei.

1170 CRITICAL STEP: Select embryos based on the developmental stage you are interested. Check for RNA expression pattern as it might depend on the orientation of each particular embryo. Be brief when checking to avoid photobleaching of RNA signal.

110. Check the autofocus and select the starting point for the $Z$ stacks. Select the total number of planes to ensure acquiring the full embryo in the axial direction.

111. Acquire brightfield images for all ROIs.

112. Acquire DAPI, RNA and fiducial barcode channels. Normally, 3D images of embryos are acquired with a $250 \mathrm{~nm}$ Z-step size, spanning a $15 \mu \mathrm{m}$ depth.

CRITICAL STEP: Make sure there is enough space in the computer storage

1180 disk. The acquisition of 30 ROIs ( 10 embryos) for 20 barcodes can take up to 1-1.5 terabytes.

? TROUBLESHOOTING

113. Set the injection procedure for the sequential imaging steps as follows: 
CRITICAL STEP: Keep the flow rate below $0.3 \mathrm{~mL} / \mathrm{min}$. The embryos can detach from the coverslip with a higher flow rate.

CRITICAL STEP: Allow for pressure stabilization before starting imaging.

\begin{tabular}{|l|l|c|c|}
\hline Step & Solution & Volume $(\mathrm{mL})$ & Flow Rate $(\mathrm{mL} / \mathrm{min})$ \\
\hline 1 & Readout probe & 1.8 & 0.15 \\
\hline 2 & Hi-M wash & 1.5 & 0.2 \\
\hline 3 & 2X SSC & 1.5 & 0.2 \\
\hline 4 & Hi-M acquisition & 0.8 & 0.15 \\
\hline
\end{tabular}

114. Stop the flow and image barcode and fiducial channels.

115. Remove fluorescent signal, following one of the two alternatives:

(A) Chemical bleaching

i. Inject $1.0 \mathrm{~mL}$ of chemical bleaching solution at a flow rate of $0.2 \mathrm{~mL} / \mathrm{min}$.

ii. Inject $1.5 \mathrm{~mL}$ of $2 X \mathrm{SCC}$ at a flow rate of $0.2 \mathrm{~mL} / \mathrm{min}$.

$1195 \quad$ (B) Photobleaching

i. Inject $1.5 \mathrm{~mL}$ of $2 \mathrm{XSCC}$ at a flow rate of $0.2 \mathrm{~mL} / \mathrm{min}$ to remove imaging buffer.

ii. Proceed to photobleaching using $100 \%$ of the laser power for $6-10 \mathrm{sec}$ in each ROI. See Experimental design section for further information.

1200 116. Repeat the steps $113-115$ for all the barcodes.

\section{Hi-M data analysis * Timing 3-4 days}

CRITICAL: Multiple types of software can be used to implement image segmentation. Here, we provide a typical script in MATLAB format.

117. Deconvolve the 3D-acquired wide-field epifluorescence images using the Huygens deconvolution software.

CRITICAL STEP: Specify the correct parameter values for deconvolution, such as pixel size, numerical aperture of the objective, excitation and emission wavelengths, and refraction index of medium.

\section{? TROUBLESHOOTING}

118. Organize stacks to include in one folder all the ROIs corresponding to one embryo.

CRITICAL STEP: Include in this folder the inf files that contain the parameters 1215 needed for the analysis.

119. Launch MATLAB and load the provided home-made script. The script is written in a modular way, where user must sequentially execute (Control+Enter) the different steps that are described from now on. Input the folder where ROIs are in "destDir" line.

$1220120 . \quad$ Launch the GUI by running the "GUI to segment DAPI masks" block. 
121. Click on "Read new ROI", wait for the program to load the image and then click on "Process".

CRITICAL STEP: Select the starting and end planes to be read in the "ImageSettings" square. If the "autoPlanes" box in the Options square is marked, it would only load the number of planes above and below the more intense defined by "zWindow" box in "ImageSettings" square.

CRITICAL STEP: If you have GPUs available for processing, tick on "GPU" box in the Options square. This will considerably reduce processing time.

122. Segment nuclei (Fig. 4). Adjust Segmentation parameters and click on

"Resegment". A visual output will be displayed showing each segmented nucleus as a mask of a different color.

CRITICAL STEP: Optimize parameters in an iterative manner by visually inspecting the segmentation output (Fig. 4c) in order to correctly segment nuclei. For our data, the typical values used are "Threshold": 0.9-1.1 (with relative threshold box ticked); "\# Voxels": 400-5000; "extent": 0.2-1, "equivDiameter": 15-100. Use the histograms on the GUI to discard outliers.

CRITICAL STEP: By ticking on "watershed" box, the segmentation is greatly improved.

\section{? TROUBLESHOOTING}

1240 123. (Optional) Due to border effects, it may be necessary to define a polygon around the embryo, in order to discard regions outside. To do so, tick on "ROI_loc" and click on "Resegment". A pop-up window will appear to manually select the polygon. Click once to define the vertices of the polygon. You can use the backspace key to delete last vertex. Double-click once you are done with the selection. An example is shown in Fig. 7.

124. Repeat steps 121-123 for all ROIs for the embryo (typically 2-4 ROIs). Change the selected ROI by changing the "nROI" bar (Fig. 4b). This whole process can also be performed in batch. In this mode, all ROls are processed without user input using the set of parameters provided in the GUI.

1250 CRITICAL: Even if batch processing we recommend to manually explore the segmentation results for each ROI after segmentation.

125. Press on "save data" button and close GUI window.

CRITICAL STEP: If "save data" is not pressed, segmented data will be lost.

126. (Optional) Dilate DAPI masks by running the corresponding block.

1255 127. Launch the spot-detection GUI to segment fiducial barcode corresponding to the first acquisition cycle (Fig. 4a). Follow the procedure as in steps 121-123 for each ROI, only this time execute the "GUI to segment internal marks DAPI" block. For historical reasons, barcodes are called "RTs" in the program.

CRITICAL STEP: Change the contrast in the "ImageSettings" square to correctly visualize the spots. A typical contrast range is between 0.1-0.999.

CRITICAL STEP: Optimize parameters in an iterative manner by visually inspecting the selection of spots (Fig. 4d) to segment all spots. A blue circle will be created around each detected spot in the raw image. Zoom in as needed. For our data, the typical values used are "Threshold": 1.5-4 (with relative 1265 threshold box unticked); "\# Voxels": 5-1000; "extent": 0.2-1, "equivDiameter": $1-50$. 


\section{? TROUBLESHOOTING}

128. Fit the detections performed in the previous step using a 3D gaussian fitting, using the "Refits RTs using 3D gaussian fitting" block.

1270 129. Launch the spot-detection GUI to segment the readouts for all cycles. Follow the procedure as in steps 121-123 for each ROI. It is possible to use "batch processing" (see next step). For our data, the typical values used are "Threshold": 1.8-5 (with relative threshold box unticked) ; "\# Voxels": 5-1000; "extent": 0.2-1, "equivDiameter": 1-50.

1275 ? TROUBLESHOOTING

130. (Optional) Once parameters are determined for a particular ROI, you can automatically segment all ROIs by clicking on "batch processing", and unticking "batchSingleROI" box in the options section of the GUI. Furthermore, by ticking on "Iterate" box on the segmentation square before pressing "batch 1280 processing", the program can automatically iterate to find the most suitable parameters for each ROI (Fig. 4a). "targetObjects" are the expected number of spots to detect, with a "tolerance" indicating the allowed range in percentage. "Alpha" is a factor by which it will change the threshold in each iteration, considering the difference between the segmented objects and "targetObjects".

1285 Its standard value is 0.001 . "maxlterations" is the maximal number of iterations it would perform, even if it didn't reach the expected number of objects, before going to the next ROI.

CRITICAL STEP: Tick "batchSingleROI" box and untick "bachSingleRT" in the options square to process all readouts for the same ROI.

1290 131. Use the spot-detection GUI to segment the fiducial barcodes in all hybridization cycles following the procedure of steps 121-123. It is possible to use "batch processing" as in previous step.

? TROUBLESHOOTING

CRITICAL STEP: It is necessary to segment each barcode for EACH ROI.

1295 Remember to press on "save data" button before closing the GUI window.

132. Fit the detections performed in the previous step using a 3D gaussian fitting by running the "Refits RTs using 3D gaussian fitting" block.

133. Calculates the drift along the cycles by running the "Correct drift using internal marker" block. It cross-correlates fiducial barcode spots with the ones from the reference cycle (the first hybridization cycle) to obtain a correction vector.

CRITICAL STEP: Select the fiducial barcode of the first cycle as reference, by changing the value of "referenceRT" variable.

134. Assess the quality of drift correction by running the "Benchmarks drift correction quality" block (Fig. 4d).

1305 ? TROUBLESHOOTING

135. Align the barcode spots from all hybridization cycles by running the next block. It uses the correction vector from the fiducial barcode spots closest to the barcode to align.

136. Segment RNA signal by running the "Segments RNA" block. A pop-up window will appear to manually select the polygon. Click once to define the vertices of the polygon. If needed, use the backspace key to delete last vertex. Double-click once done with the selection. 
137. Build results structure.

138. Control how successful was the clustering of spots in single nuclei by running the "Assesses results quality" block. A high percentage (over $80 \%$ ) of clustered barcode spots is expected.

\section{? TROUBLESHOOTING}

139. Assign detected readouts to the segmented nuclei, and build the CellID structure, by running the "Finds RTs for each Cell mask in each ROI" block .

1320 140. Save segmented data, by saving MATLAB's workspace.

141. Launch merfish_cellID_analysis_v4.m analysis software in MATLAB. The script is written in a modular way, where user must sequentially execute (Control+Enter) the different steps that are described from now on. Place the files obtained in previous step in a folder, and add the folder path to the data 1325 path in the program.

142. Load datasets, by running the first section.

CRITICAL STEP: Load in this section the data paths that contain the genomic coordinates of the readout probes used in data acquisition.

143. Set parameters, by running "Sets parameters" section. They are defined by default, but can be adapted for each experiment.

CRITICAL STEP: Choose the correct value for the p.process variable (RNAon, RNAoff, or none), depending on whether nuclei containing RNA staining are to be analyzed separately from those who do not (RNAon and RNAoff respectively). By choosing the value "none", both type of nuclei will be

\section{5 processed together.}

144. Run the "Loops over cells and detects clusters" section. This will group barcodes in clusters.

145. Order readouts according to their genomic position, by running the dedicated section. This will allow to assign to each barcode the correct genomic coordinates, and later construct distance matrices.

146. Run the "Populates distanceMatrix" section. Then, run the "Calculates mean distance matrix and contact probability matrix from distanceMatrix structure".

147. Plot genomic distances versus mean physical distances using the corresponding block.

1345 148. Plot contact probability versus genomic distance by running the corresponding block.

149. Plot the normalised distance matrix and normalised contact probability matrix by running "Plots the normalised distance matrix and normalised contact probability matrices" section.

\section{Timing}

Steps 1-7, design of Oligopaint libraries: $4-5 \mathrm{~h}$

1355 Steps 8-39, amplification of Oligopaints: 4-5 days

Steps 40-50, embryo collection and fixation: $2-3 \mathrm{~h}$

Steps 51-77, RNA in situ hybridization: 2.5 days 
Steps 78-92, DNA in situ hybridization: 1.5 days

Steps 93-100, attachment of embryos: $1 \mathrm{~h}$

1360 Steps 101-116, Hi-M data acquisition: $\sim 1 \mathrm{~h}$ per barcode for 25 ROIs

Steps 117-149, Hi-M data analysis: 0.5 day per embryo (typically 3-4 ROIs)

\section{Troubleshooting}

Table 6. Troubleshooting table

\begin{tabular}{|c|c|c|c|}
\hline Step & Problem & Possible reason & Solution \\
\hline 16,22 & $\begin{array}{l}\text { Non-specific bands } \\
\text { appearing during PCR } \\
\text { amplification }\end{array}$ & $\begin{array}{l}\text { Mis-priming due to } \\
\text { over-amplification }\end{array}$ & $\begin{array}{l}\text { Reduce the } \\
\text { number of } \\
\text { cycles. Run a } \\
\text { small scale } \\
\text { PCR to define } \\
\text { the optimal } \\
\text { number } \\
\text { Increase } \\
\text { temperature of } \\
\text { annealing } \\
\text { Perform a } \\
\text { Mg } \\
\text { find the right } \\
\text { concentration. } \\
\text { For GC-rich } \\
\text { adding a final } \\
\text { concentration } \\
\text { of } 5 \% \text { (v/v) } \\
\text { DMSO to the } \\
\text { mixture might } \\
\text { help. }\end{array}$ \\
\hline 26 & $\begin{array}{l}\text { RNA is degraded or } \\
\text { absent }\end{array}$ & RNA degradation & $\begin{array}{l}\text { Maintain } \\
\text { RNAse-free } \\
\text { conditions }\end{array}$ \\
\hline $\begin{array}{l}100,106 \\
108\end{array}$ & $\begin{array}{l}\text { Embryos detach from } \\
\text { chamber }\end{array}$ & $\begin{array}{l}\text { Embryos have remaining } \\
\text { oil }\end{array}$ & $\begin{array}{l}\text { Carefully } \\
\text { remove all the } \\
\text { oil after the } \\
\text { O/N incubation } \\
\text { with the } \\
\text { primary probe. } \\
\text { Be sure that } \\
\text { embryos are }\end{array}$ \\
\hline
\end{tabular}




\begin{tabular}{|c|c|c|c|}
\hline & & $\begin{array}{l}\text { Embryos or coverslip } \\
\text { were too wet } \\
\text { Coverslip coating is not } \\
\text { effective } \\
\text { Flow rate/pressure was } \\
\text { too high }\end{array}$ & $\begin{array}{l}\text { stored in PBS. } \\
\text { Dry with paper } \\
\text { tissue around } \\
\text { the embryos or } \\
\text { wait a few } \\
\text { minutes until } \\
\text { the buffer } \\
\text { evaporates. } \\
\text { Keep the } \\
\text { coverslip at } \\
\text { distance when } \\
\text { drying with the } \\
\text { flame. } \\
\text { Otherwise, the } \\
\text { coverslip can } \\
\text { deform and } \\
\text { polylysine will } \\
\text { not adhere } \\
\text { properly } \\
\text { Make sure to } \\
\text { check flow } \\
\text { rates for all the } \\
\text { valves being } \\
\text { used before } \\
\text { starting the } \\
\text { experiment. } \\
\text { Wash valves } \\
\text { that are not } \\
\text { optimal with } \\
\text { filtered water to } \\
\text { unclog them. }\end{array}$ \\
\hline 112 & $\begin{array}{l}\text { Autofluorescence is too } \\
\text { high }\end{array}$ & $\begin{array}{l}\text { Formaldehyde used for } \\
\text { fixation was not } \\
\text { methanol-free } \\
\text { Wash steps were not } \\
\text { effective }\end{array}$ & $\begin{array}{l}\text { Collect and fix } \\
\text { new embryos } \\
\text { using } \\
\text { formaldehyde } \\
\text { methanol free } \\
\text { Label new } \\
\text { embryos, } \\
\text { carefully } \\
\text { following the } \\
\text { washing steps }\end{array}$ \\
\hline 112 & No RNA signal & RNA degradation & $\begin{array}{l}\text { Ensure } \\
\text { RNAse-free } \\
\text { conditions }\end{array}$ \\
\hline
\end{tabular}




\begin{tabular}{|c|c|c|c|}
\hline & & $\begin{array}{l}\text { RNA probe degradation } \\
\text { Embryo is not well } \\
\text { oriented }\end{array}$ & $\begin{array}{l}\text { Control } \\
\text { temperature } \\
\text { and time very } \\
\text { precisely when } \\
\text { denaturing } \\
\text { probe. Do not } \\
\text { denature } \\
\text { re-used probes } \\
\text { Orientation on } \\
\text { the coverslip is } \\
\text { random, which } \\
\text { can be limiting } \\
\text { when RNA } \\
\text { expression has } \\
\text { a spatial } \\
\text { pattern. Put } \\
\text { more embryos } \\
\text { to increase the } \\
\text { chance to find } \\
\text { them in the } \\
\text { desired } \\
\text { position. } \\
\text { Alternatively, } \\
\text { try to orient } \\
\text { them } \\
\text { (ventral/dorsal) } \\
\text { before } \\
\text { attaching them } \\
\text { to the } \\
\text { coverslip. }\end{array}$ \\
\hline & & RNA is not expressed & $\begin{array}{l}\text { Check the } \\
\text { developmental } \\
\text { time of the } \\
\text { selected } \\
\text { embryos }\end{array}$ \\
\hline 112 & $\begin{array}{l}\text { Bright spots on the field of } \\
\text { view }\end{array}$ & $\begin{array}{l}\text { Coverslip was not } \\
\text { properly cleaned }\end{array}$ & $\begin{array}{l}\text { Prepare a new } \\
\text { coverslip, } \\
\text { cleaning it } \\
\text { thoroughly with } \\
\text { acetone. Use } \\
70 \%(\mathrm{v} / \mathrm{v}) \\
\text { ethanol: } \mathrm{ddH}_{2} \mathrm{O} \\
\text { to rinse it } \\
\text { before drying it } \\
\text { in the flame. }\end{array}$ \\
\hline
\end{tabular}




\begin{tabular}{|c|c|c|c|}
\hline 112 & No DAPI signal & $\begin{array}{l}\text { Formamide washes away } \\
\text { DAPI }\end{array}$ & $\begin{array}{l}\text { Acquire DAPI } \\
\text { before } \\
\text { incubating with } \\
\text { hybridization } \\
\text { solution }\end{array}$ \\
\hline 114 & No barcode spots & $\begin{array}{l}\text { Secondary oligos are } \\
\text { degraded or not the } \\
\text { correct ones }\end{array}$ & $\begin{array}{l}\text { Check for the } \\
\text { sequences } \\
\text { employed both } \\
\text { in primary and } \\
\text { secondary } \\
\text { oligos }\end{array}$ \\
\hline 114 & $\begin{array}{l}\text { Fluorescent signal } \\
\text { bleaches }\end{array}$ & $\begin{array}{l}\text { Exposure time was too } \\
\text { long and/or the laser } \\
\text { power was too high; the } \\
\text { number of planes was too } \\
\text { high } \\
\text { Imaging buffer is no } \\
\text { longer active }\end{array}$ & $\begin{array}{l}\text { Optimize } \\
\text { parameters in } \\
\text { a control } \\
\text { experiment } \\
\text { Imaging buffer } \\
\text { should be } \\
\text { stored under a } \\
\text { protective layer } \\
\text { of mineral oil } \\
\text { and changed } \\
\text { by a freshly } \\
\text { prepared one } \\
\text { every } 12 \text { - } 15 \\
\text { hours. }\end{array}$ \\
\hline 114 & $\begin{array}{l}\text { Pressure is too high, flow } \\
\text { rate is too low }\end{array}$ & Air bubble in the system & $\begin{array}{l}\text { In-between } \\
\text { experiments, } \\
\text { wash the } \\
\text { system with } \\
50 \% \text { ethanol, it } \\
\text { would facilitate } \\
\text { bubble removal } \\
\text { and bacterial } \\
\text { growth at the } \\
\text { same time. } \\
\text { Before starting } \\
\text { the injection } \\
\text { procedure, } \\
\text { pass } 2 X \text { SCC } \\
\text { in each valve } \\
\text { and check that } \\
\text { the flow rate is } \\
\text { stable. }\end{array}$ \\
\hline
\end{tabular}




\begin{tabular}{|c|c|c|c|}
\hline & & $\begin{array}{l}\text { Dirt or salt deposits in the } \\
\text { system }\end{array}$ & $\begin{array}{l}\text { Filter all } \\
\text { solutions } \\
\text { before injecting } \\
\text { them. Wash } \\
\text { the system } \\
\text { with filtered } \\
\text { water to } \\
\text { remove } \\
\text { anything that } \\
\text { may disturb the } \\
\text { flow. }\end{array}$ \\
\hline 112,114 & Autofocus is lost & $\begin{array}{l}\text { Embryos are too far from } \\
\text { each other in the } \\
\text { coverslip. } \\
\text { Light scattering due to } \\
\text { additional reflection of the } \\
785 \text { nm laser (autofocus } \\
\text { line) on the embryo. }\end{array}$ & $\begin{array}{l}\text { When defining } \\
\text { the ROIs, } \\
\text { avoid to select } \\
\text { consecutively } \\
\text { very distant } \\
\text { embryos. } \\
\text { For each } \\
\text { embryo, define } \\
\text { a nearby } \\
\text { reference ROI } \\
\text { where the } \\
\text { autofocus } \\
\text { signal is not } \\
\text { affected. }\end{array}$ \\
\hline 114 & $\begin{array}{l}\text { Fluorescent spots after } \\
\text { bleaching step }\end{array}$ & $\begin{array}{l}\text { The selected bleaching } \\
\text { strategy is not effective }\end{array}$ & $\begin{array}{l}\text { Choice of } \\
\text { bleaching will } \\
\text { depend on } \\
\text { factors such as } \\
\text { number of } \\
\text { ROls, probes } \\
\text { per barcode or } \\
\text { experimental } \\
\text { model. } \\
\text { Optimization } \\
\text { should be } \\
\text { needed. }\end{array}$ \\
\hline 117 & Deconvolution artifacts & $\begin{array}{l}\text { Deconvolution } \\
\text { parameters were not } \\
\text { optimal }\end{array}$ & $\begin{array}{l}\text { Check the } \\
\text { excitation and } \\
\text { emission } \\
\text { wavelengths. } \\
\text { Check pixel } \\
\text { size and Z step } \\
\text { used. }\end{array}$ \\
\hline
\end{tabular}




\begin{tabular}{|c|c|c|c|}
\hline 122 & $\begin{array}{l}\text { Nuclei are segmented } \\
\text { incorrectly }\end{array}$ & $\begin{array}{l}\text { Threshold parameters } \\
\text { are not optimal }\end{array}$ & $\begin{array}{l}\text { Increase } \\
\text { threshold value } \\
\text { over } 1 . \\
\text { Extend bounds } \\
\text { for number of } \\
\text { voxels. }\end{array}$ \\
\hline $\begin{array}{l}127,129 \\
131\end{array}$ & Low spot detection & $\begin{array}{l}\text { Efficiency of labeling is } \\
\text { low } \\
\text { The } Z \text { range is too small } \\
\text { to capture the entire layer } \\
\text { of cells of the embryo. }\end{array}$ & $\begin{array}{l}\text { FISH } \\
\text { conditions } \\
\text { should be } \\
\text { optimized. } \\
\text { Ramp } \\
\text { temperature } \\
\text { over } \\
\text { Use DAPI } \\
\text { staining to } \\
\text { correctly define } \\
\text { the stack size }\end{array}$ \\
\hline 127 & $\begin{array}{l}\text { Detection algorithm } \\
\text { under/over counts }\end{array}$ & $\begin{array}{l}\text { Threshold parameters } \\
\text { are not optimized } \\
\text { Background is too high or } \\
\text { SNR is below } 3 \\
\text { There are several false } \\
\text { detections }\end{array}$ & $\begin{array}{l}\text { Manually } \\
\text { adjust the } \\
\text { parameters } \\
\text { interactively. } \\
\text { Use the zoom } \\
\text { to visualize the } \\
\text { spots. } \\
\text { Deconvolution } \\
\text { can greatly } \\
\text { increase SNR } \\
\text { ratio } \\
\text { Increase } \\
\text { threshold. } \\
\text { Change } \\
\text { eccentricity } \\
\text { upper bound to } \\
0.8 \text { - } 0.9 \text {, until } \\
\text { spurious } \\
\text { detections are } \\
\text { filtered. }\end{array}$ \\
\hline 134 & $\begin{array}{l}\text { Drift correction is not good } \\
\text { enough }\end{array}$ & $\begin{array}{l}\text { Fiducial barcode was } \\
\text { photobleached during } \\
\text { acquisition cycles }\end{array}$ & $\begin{array}{l}\text { Make sure } \\
\text { Hi-M } \\
\text { acquisition } \\
\text { solution is } \\
\text { stored under a } \\
\text { mineral oil }\end{array}$ \\
\hline
\end{tabular}




\begin{tabular}{|c|c|c|c|}
\hline & & (1) & $\begin{array}{l}\text { layer and } \\
\text { renewed every } \\
\text { 12 h } \\
\text { Imaging steps } \\
\text { should be } \\
\text { optimized, by } \\
\text { reducing laser } \\
\text { power or } \\
\text { acquisition } \\
\text { time. } \\
\text { Fiducial } \\
\text { barcode should } \\
\text { be designed to } \\
\text { have higher } \\
\text { number of } \\
\text { oligos } \\
\text { (150-300) } \\
\\
\text { Resegment the } \\
\text { fiducial } \\
\text { barcode using } \\
\text { optimized } \\
\text { parameters. } \\
\text { Use visual } \\
\text { inspection to } \\
\text { make sure it is } \\
\text { the case }\end{array}$ \\
\hline 138 & $\begin{array}{l}\text { Spots are not well } \\
\text { clustered }\end{array}$ & $\begin{array}{l}\text { Barcode segmentation } \\
\text { was not efficient }\end{array}$ & $\begin{array}{l}\text { Resegment } \\
\text { barcodes using } \\
\text { optimized } \\
\text { parameters. } \\
\text { Use visual } \\
\text { inspection to } \\
\text { make sure it is } \\
\text { the case, and } \\
\text { make sure } \\
\text { there are no } \\
\text { false } \\
\text { detections. }\end{array}$ \\
\hline
\end{tabular}


This protocol provides a detailed description of the steps required design Oligopaint probes, stain and image simultaneously RNA and DNA, and to segment nuclei, RNA and multiple barcodes in thousand of cells in an intact organism.

A typical set of results is shown in Fig. 9. It consists of matrices of pairwise absolute contact probability, pairwise distance maps, and ratio between standard deviation and mean pairwise distances. Critically, the simultaneous detection of RNA expression of a target gene allows for the analysis of nuclei according to their 1380 transcriptional state. 


\section{Author contributions statements}

1385 A.M.C.G., and M.N. designed the experiments. A.M.C.G. and M.N. designed the oligopaint probes. C.H. amplified and purified the oligopaints libraries. A.M.C.G., C.H., S.M.E. and J.G. developed the RNA/DNA staining protocol, A.M.C.G., S.M.E., J.G. and D.I.C. conducted the experiments. J.-B.F. designed and built the microscopy setup and acquisition software. M.N. developed the software for image analysis. A.M.C.G., and

1390 J.G. analyzed the data. A.M.C.G., D.I.C. and M.N. wrote the manuscript. All the authors reviewed and commented on the manuscript.

\section{Acknowledgments}

1395 This project has received funding from the European Research Council (ERC) under the European Union's Horizon 2020 Research and Innovation Program (grant ID 724429). This work also benefited from support from Labex EpiGenMed, an "Investments for the Future" program (grant ID ANR-10-LABX-12-01). We acknowledge the France-Biolmaging infrastructure supported by the French National

1400 Research Agency (grant ID ANR-10-INBS-04, "Investments for the Future"). A.M.C.G. is at present a postdoctoral fellow of Consejo Nacional de Investigaciones Científicas y Técnicas (CONICET).

\section{Competing interests}

The authors declare no competing interests.

\section{Data and code availability}

1410 The code used and described in this paper as well as the experimental dataset used to construct the Fig. 9 have been uploaded to: https://doi.org/10.17632/5f5hd9yj3z.1\#folder-26d1f8c0-fc58-4b87-8c4f-cd8a294a555.S oftware Additional advice on how to use it can be obtained from the authors upon reasonable request. Further information and requests for resources, reagents and

1415 software should be directed to and will be fulfilled by the Lead Contact, Marcelo Nollmann (marcelo.nollmann@cbs.cnrs.fr). 


\section{Legends to the Figures}

\section{Figure 1. Outline of the Hi-M protocol}

Schematic description of the main steps in the Hi-M protocol.

\section{Figure 2. Design and amplification of Oligopaints}

a,Upper panel, schematic structure of oligos: 1) a forward and reverse 20-nt universal

1430 priming region in blue-green, 2) a 32-nt readout sequence in blue (x2) and 3) a 42-nt genome homology variable region in black. Lower panel, schematic description of the steps to design an oligopool. b, Upper panel, oligopool amplification scheme.. Blue-green represents universal priming region common to all barcodes whereas blue, amber and burgundy represent barcode-specific readout sequences. Lower panel,

1435 schematic description of main steps involved. c, Example of an agarose gel electrophoresis result for the small scale limited-cycle PCR step. "L" is the DNA ladder or molecular weight size marker. A band of the expected size (166-nt in this case) is observed between the 100- and 200-nt bands of the ladder. In cycles 13 and 14 a second, non-specific band of $\sim 300$-nt begins to appear. Therefore, 11 amplification

1440 cycles (at PCR cycle 12) were chosen for this specific amplification reaction. d, Example of an agarose gel electrophoresis result for the large scale limited-cycle PCR step. "L" is the ladder as in panel c. Lane 1 and 2 correspond to a PCR performed without or with template, respectively. dNTPs are observed at the bottom. Lane 3 corresponds to column-purified PCR product. e, Example of an Urea PAGE result. "L"

1445 is the low range ssRNA ladder. Bands from lanes 1-4 appear close to the height of the 150-nt band from the ladder. Lane 1 corresponds to $200 \mathrm{ng}$ of emulsion PCR break, lane 2 to $200 \mathrm{ng}$ of RNA product from in vitro transcription (note the higher size due to the presence of the T7-promoter region), lanes 3 and 4 to $200 \mathrm{ng}$ of SSDNA before and after precipitation, respectively.

\section{Figure 3. Procedure for attaching embryos to the microfluidics chamber}

Where it corresponds, the sequence is indicated as i, ii, iii and iv. a, Embryo attachment. (Step 94) Add poly-L-lysine solution to coverslip. (Step 96) Cut an agarose pad and transfer 20-30 embryos to the agarose pad. (Step 97) Use metal tweezers to

1455 align the embryos using a binocular microscope to visualize them. (Step 98) Dry the embryos using a paper tissue. (Step 99) Attach the embryos to a poly-L-lysine-coated coverslip by gently pressing coverslip against the agarose pad. b, Embryo mounting to chamber. (Step 102) Open the microfluidics chamber by unscrewing it. Carefully remove the glass coverslip from the chamber. (Step 103) Remove the plastic spacer

1460 and dry it thoroughly with a paper tissue. (Step 104) Put back the dried spacer and mount the coverslip with the attached embryos. (Step 105) Screw the chamber and mount it to the microscope stage. (Step 106) Flow 2X SSC buffer through the chamber by slowly aspirating with a syringe. 
a, Primary oligopool is hybridized on the bench to genomic DNA. b, A readout oligo (blue), bearing a fluorophore (red star), specifically binds to the blue readout barcode. c, Once hybridized, images are recorded for all ROls. d, The fluorophore on the readout oligo is chemically cleaved or alternatively, photobleached. e, A new

1470 hybridization cycle starts with a different readout oligo, now targeting the ambar barcode.

\section{Figure 5. Hi-M setup}

In the center, an image of the Hi-M setup. White arrows indicate the location of the 60X 1475 water-immersion objective (not visible). The microfluidics tubing is highlighted in yellow. Color rectangles zoom into key components. (i) The solid state lasers lasers are combined by dichroic mirrors and an acousto-optic filter (AOTF) is used to switch the different laser lines on/off and to change intensity. (ii) Beams are expanded by a telescope and focused at the back-focal-plane of a 60X objective. (iii) Flow is created

1480 by a negative pressure pump at the outlet. Liquid is withdrawn from the inlet of a valve, (iv), passes through the FCS2 flow chamber (v), the online flow-unit and is then discarded into the bottle in the outlet.

\section{Figure 6. Hi-M image acquisition flowchart}

1485 Left, sequence of steps required for sample mounting, microscope set-up and DAPI/RNA signal acquisition (violet boxes). Right, sequence of steps needed for the sequential barcode acquisition (yellow boxes).

\section{Figure 7. Hi-M image analysis flowchart}

1490 Sequence of steps required for image analysis (spot detection and registration). Violet boxes indicate key steps, yellow boxes indicate refinement of obtained masks (either by dilating the nuclei mask or by 3D Gaussian fitting of barcode positions), whereas pink boxes indicate quality check steps.

\section{Figure 8. Data analysis}

a, MATLAB GUI for image analysis employed in steps 120-125, 127, 129 and 131. The panels show the center buttons, the processing options, image and segmentation parameters that are used to segment nuclei or barcodes. $\mathbf{b}, \mathrm{ROI}$ selection bar. $\mathrm{nRT}$ is the corresponding barcode whereas $\mathrm{nROI}$ is the selected ROI. c, Typical example of

1500 nuclei segmentation. Each nuclei mask is represented with a different color. d, Example of a barcode image Z-projection after segmentation. The intensity is represented in a color code that ranges from black to orange to white. Identified barcodes are marked with a blue circle around them. e, RNA signal segmentation, performed in a pop-up window. RNA-positive nuclei are manually selected by a 
1505 blue-line polygon. Panels $\mathrm{c}, \mathrm{d}$ and e correspond to the same embryo, labeled with DAPI, DNA and RNA, respectively. Scale bar, $20 \mu \mathrm{m}$. f, Drift correction quality. Left panel, histogram of standard deviation between fiducial barcodes after drift correction, expressed in pixels. Pixel size is $108 \mathrm{~nm}$. Right panel, boxplots of the residual error in xyz between fiducial barcodes after drift correction, applying only a global, or a global

1510 and a local correction ${ }^{3}$.

\section{Figure 9. Hi-M output}

a, Hi-M absolute contact probability maps from nuclei expressing ('on', top panel) or

1515 not expressing ('off', lower panel) the target RNA. The absolute contact probability was estimated as described previously ${ }^{41}$. The color scale indicates absolute contact probability as indicated in the scale on the right. b. Hi-M normalized mean physical distance map from nuclei expressing ('on', top panel) or not expressing ('off', lower panel) the target RNA. Normalization is achieved by subtracting expected from

1520 observed distances. The expected distance was obtained by fitting a physical versus genomic distance curve ${ }^{3}$. The color scale indicates distances lower (magenta) or higher (cyan) than expected. Normalized distances are shown in nanometers as indicated in the scale on the right. c, Hi-M ratio between standard deviation and mean pairwise distances from nuclei expressing ('on', top panel) or not expressing ('off',

1525 lower panel) the target RNA. The color scale ranges from 0.5 (blue), 0 (white) to 1.5 (red). Panels appearing on this Figure have been reproduced with permission from ${ }^{3}$.

1530 Supplementary information

Supplementary Table 1. Fluorescent readout probe sequences.

1535 Supplementary Table 2. Readout region sequences.

Supplementary Table 3. Universal priming region sequences. 


\section{References}

1. Bonev, B. \& Cavalli, G. Organization and function of the 3D genome. Nat. Rev. Genet. 17, 772 (2016).

2. Giorgetti, L. \& Heard, E. Closing the loop: 3C versus DNA FISH. Genome Biol. 17, 215 (2016).

1545 3. Cardozo Gizzi, A. M. et al. Microscopy-Based Chromosome Conformation Capture Enables Simultaneous Visualization of Genome Organization and Transcription in Intact Organisms. Mol. Cell 74, 212-222.e5 (2019).

4. Bintu, B. et al. Super-resolution chromatin tracing reveals domains and cooperative interactions in single cells. Science 362, (2018).

1550 5. Nir, G. et al. Walking along chromosomes with super-resolution imaging, contact maps, and integrative modeling. PLoS Genet. 14, e1007872 (2018).

6. Mateo, L. J. et al. Visualizing DNA folding and RNA in embryos at single-cell resolution. Nature 568, 49-54 (2019).

7. Beliveau, B. J. et al. Versatile design and synthesis platform for visualizing genomes with Oligopaint FISH probes. Proc. Natl. Acad. Sci. U. S. A. 109, 21301-21306 (2012).

8. Beliveau, B. J. et al. Single-molecule super-resolution imaging of chromosomes and in situ haplotype visualization using Oligopaint FISH probes. Nature Communications 6, (2015).

1560 9. Lubeck, E., Coskun, A. F., Zhiyentayev, T., Ahmad, M. \& Cai, L. Single-cell in situ RNA profiling by sequential hybridization. Nat. Methods 11, 360-361 (2014).

10. Chen, K. H., Boettiger, A. N., Moffitt, J. R., Wang, S. \& Zhuang, X. RNA imaging. Spatially resolved, highly multiplexed RNA profiling in single cells. Science $\mathbf{3 4 8 ,}$ 
aaa6090 (2015).

1565 11. Moffitt, J. R. et al. Molecular, spatial, and functional single-cell profiling of the hypothalamic preoptic region. Science 362, (2018).

12. Rosin, L. F., Nguyen, S. C. \& Joyce, E. F. Condensin II drives large-scale folding and spatial partitioning of interphase chromosomes in Drosophila nuclei. PLOS Genet. 14, e1007393 (2018).

1570 13. Kishi, J. Y., Beliveau, B. J., Lapan, S. W., West, E. R. \& Zhu, A. SABER enables highly multiplexed and amplified detection of DNA and RNA in cells and tissues. bioRxiv (2018).

14. Fields, B. D., Nguyen, S. C., Nir, G. \& Kennedy, S. A multiplexed DNA FISH strategy for assessing genome architecture in Caenorhabditis elegans. Elife 8, 1575 (2019).

15. Lidke, D. S. et al. Sequential Super-Resolution Imaging using DNA Strand Displacement. bioRxiv 237560 (2017). doi:10.1101/237560

16. Roohi, J., Cammer, M., Montagna, C. \& Hatchwell, E. An improved method for generating BAC DNA suitable for FISH. Cytogenet. Genome Res. 121, 7-9 $1580 \quad$ (2008).

17. Bienko, M. et al. A versatile genome-scale PCR-based pipeline for high-definition DNA FISH. Nature Methods 10, 122-124 (2013).

18. Wang, S. et al. Spatial organization of chromatin domains and compartments in single chromosomes. Science 353, 598-602 (2016).

1585 19. Shah, S. et al. Dynamics and Spatial Genomics of the Nascent Transcriptome by Intron seqFISH. Cell 174, 363-376.e16 (2018).

20. Eng, C.-H. L., Shah, S., Thomassie, J. \& Cai, L. Profiling the transcriptome with RNA SPOTs. Nature Methods 14, 1153-1155 (2017).

21. Wu, X., Mao, S., Ying, Y., Krueger, C. J. \& Chen, A. K. Progress and Challenges 
for Live-cell Imaging of Genomic Loci Using CRISPR-based Platforms. Genomics Proteomics Bioinformatics (2019). doi:10.1016/j.gpb.2018.10.001

22. Ma, H. et al. Multiplexed labeling of genomic loci with dCas9 and engineered sgRNAs using CRISPRainbow. Nat. Biotechnol. 34, 528-530 (2016).

23. Germier, T. et al. Real-Time Imaging of a Single Gene Reveals

1595 Transcription-Initiated Local Confinement. Biophys. J. 113, 1383-1394 (2017).

24. Chen, H. et al. Dynamic interplay between enhancer-promoter topology and gene activity. Nature Genetics 50, 1296-1303 (2018).

25. Yunger, S., Rosenfeld, L., Garini, Y. \& Shav-Tal, Y. Single-allele analysis of transcription kinetics in living mammalian cells. Nat. Methods 7, 631 (2010).

1600 26. Larson, D. R., Zenklusen, D., Wu, B., Chao, J. A. \& Singer, R. H. Real-time observation of transcription initiation and elongation on an endogenous yeast gene. Science 332, 475-478 (2011).

27. Fukaya, T., Lim, B. \& Levine, M. Enhancer Control of Transcriptional Bursting. Cell 166, 358-368 (2016).

1605 28. Saad, H. et al. DNA dynamics during early double-strand break processing revealed by non-intrusive imaging of living cells. PLoS Genet. 10, e1004187 (2014).

29. Boyle, S., Rodesch, M. J., Halvensleben, H. A., Jeddeloh, J. A. \& Bickmore, W. A. Fluorescence in situ hybridization with high-complexity repeat-free oligonucleotide probes generated by massively parallel synthesis. Chromosome Res. 19, 901-909 (2011).

30. Rouillard, J.-M., Zuker, M. \& Gulari, E. OligoArray 2.0: design of oligonucleotide probes for DNA microarrays using a thermodynamic approach. Nucleic Acids Res. 31, 3057-3062 (2003).

1615 31. Gelali, E. et al. iFISH is a publically available resource enabling versatile DNA 
FISH to study genome architecture. Nature Communications 10, (2019).

32. Beliveau, B. J. et al. OligoMiner provides a rapid, flexible environment for the design of genome-scale oligonucleotide in situ hybridization probes. Proc. Natl. Acad. Sci. U. S. A. 115, E2183-E2192 (2018).

1620 33. Raj, A., van den Bogaard, P., Rifkin, S. A., van Oudenaarden, A. \& Tyagi, S. Imaging individual mRNA molecules using multiple singly labeled probes. Nat. Methods 5, 877-879 (2008).

34. Moffitt, J. R. \& Zhuang, X. RNA Imaging with Multiplexed Error-Robust Fluorescence In Situ Hybridization (MERFISH). Methods Enzymol. 572, 1-49 $1625 \quad$ (2016).

35. Trcek, T., Lionnet, T., Shroff, H. \& Lehmann, R. mRNA quantification using single-molecule FISH in Drosophila embryos. Nat. Protoc. 12, 1326-1348 (2017).

36. Shpiz, S., Lavrov, S. \& Kalmykova, A. Combined RNA/DNA fluorescence in situ hybridization on whole-mount Drosophila ovaries. Methods Mol. Biol. 1093, 1630 161-169 (2014).

37. Boettiger, A. N. \& Levine, M. Rapid transcription fosters coordinate snail expression in the Drosophila embryo. Cell Rep. 3, 8-15 (2013).

38. Bantignies, F. \& Cavalli, G. Topological organization of Drosophila Hox genes using DNA fluorescent in situ hybridization. Methods Mol. Biol. 1196, 103-120 1635 (2014).

39. Moffitt, J. R. et al. High-throughput single-cell gene-expression profiling with multiplexed error-robust fluorescence in situ hybridization. Proceedings of the National Academy of Sciences 113, 11046-11051 (2016).

40. Fung, J. C., Marshall, W. F., Dernburg, A., Agard, D. A. \& Sedat, J. W.

1640 Homologous chromosome pairing in Drosophila melanogaster proceeds through multiple independent initiations. J. Cell Biol. 141, 5-20 (1998). 
41. Cattoni, D. I. et al. Single-cell absolute contact probability detection reveals chromosomes are organized by multiple low-frequency yet specific interactions. Nat. Commun. 8, 1753 (2017). 


\section{a}

\section{Design of Oligopaints}

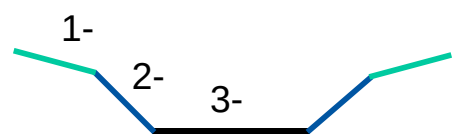

\section{Download Oligopaint scripts} and .bed files

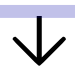

Obtain the oligos sequences corresponding to each barcode

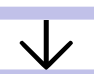

Create a text file with the readout sequences from each barcode

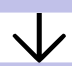

Add the readout sequences corresponding to each barcode<smiles>C1C2CC12</smiles>

Add the universal primer sequences to the whole library

$$
\downarrow
$$

Order the Oligopool

\section{Small scale limited-cycle PCR}

\begin{tabular}{llllllll}
\hline 8 & 9 & 10 & 11 & 12 & 13 & 14
\end{tabular} d

\section{Large scale} limited-cycle PCR e

Urea PAGE

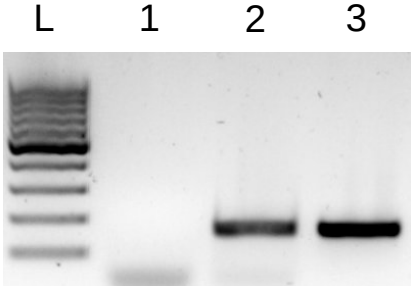

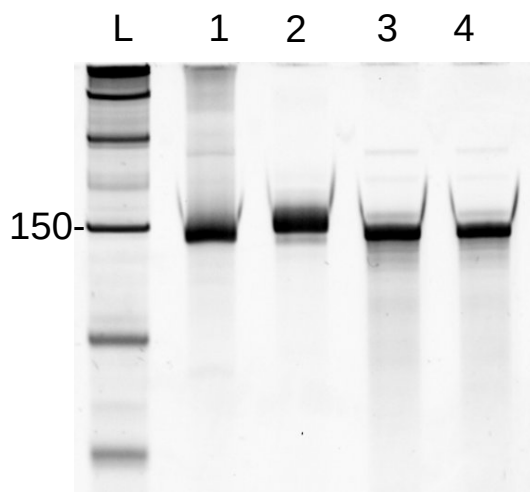

Emulsion PCR

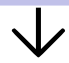

Small scale limited-cycle PCR

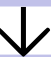

Large scale limited-cycle PCR

In vitro trancription

Reverse trancription

RNA alkaline hydrolysis

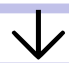

DNA precipitation and concentration 
Figure 3

a
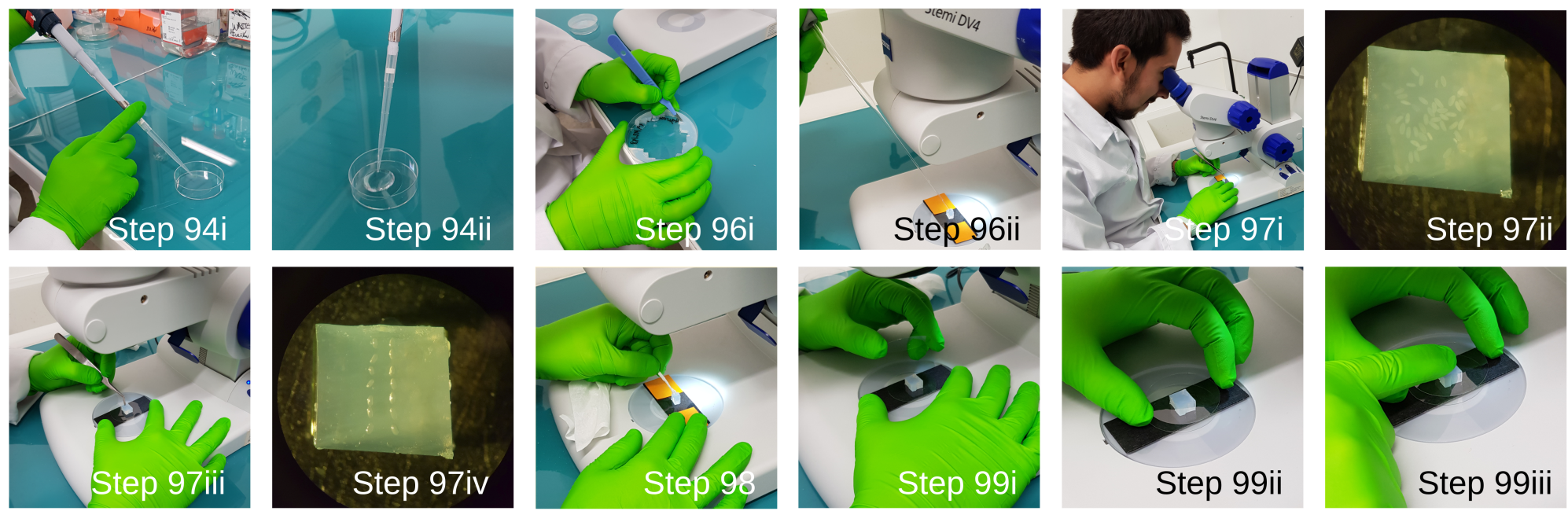

b
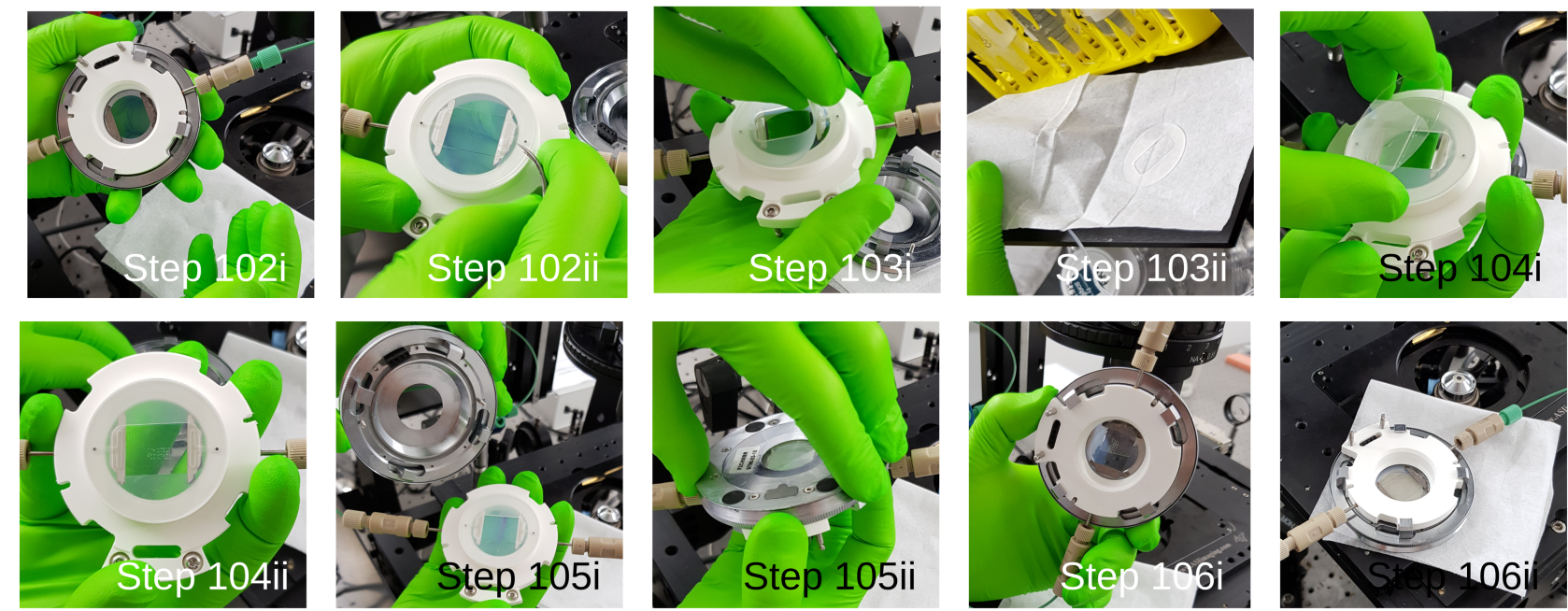
Figure 4

a

DNA FISH

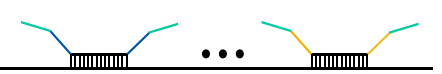

e

Xth cycle hybridization

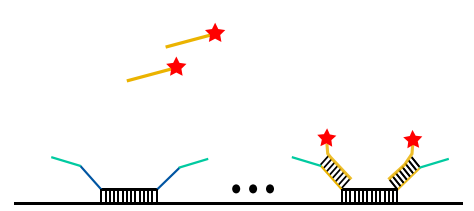

b
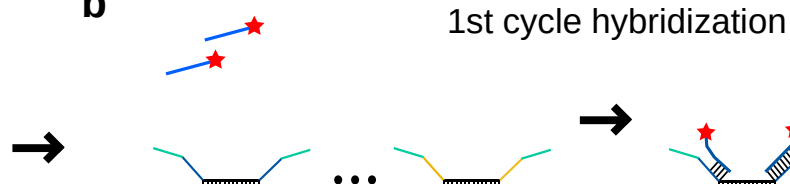

d

Fluorophore bleaching

C

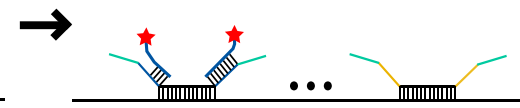

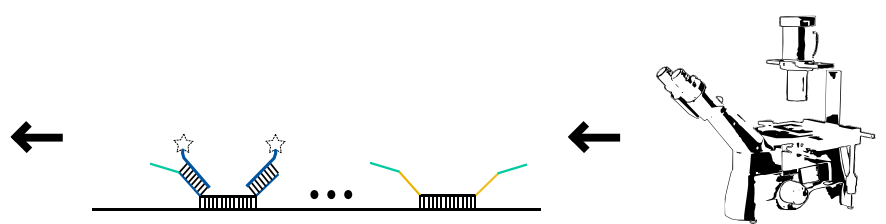
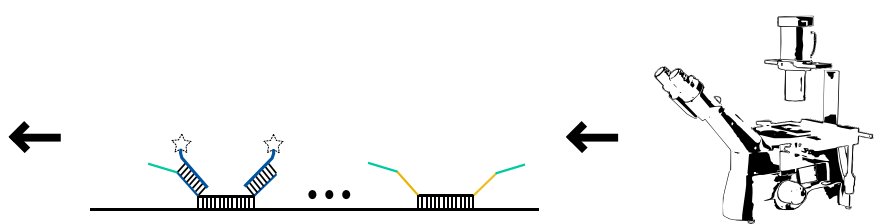
Figure 6

Mount the sample into

microfluidics chamber

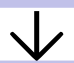

Mount chamber into microscope

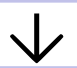

Define buffers and recognition/imaging oligos injection valves

$\downarrow$

Select ROIs

$\downarrow$

Select the starting $Z$ point and check autofocus

$\downarrow$

Acquire brightfield

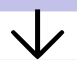

Acquire DAPI, RNA signal and fiducial barcode

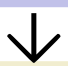

Start sequential acquisition

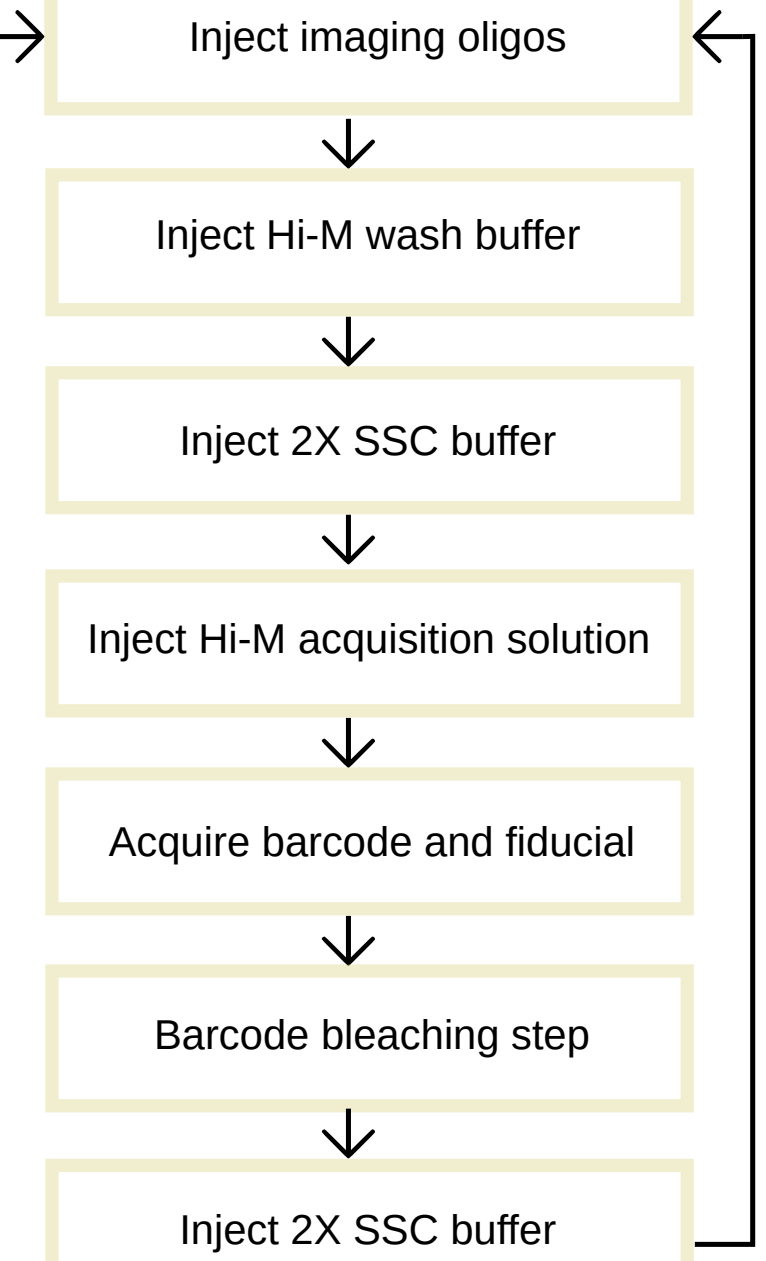

Inject 2X SSC buffer 
Figure 7

Deconvolution of images

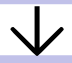

Segment nuclei

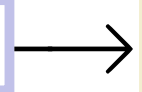

Dilate nuclei

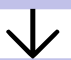

Segment fiducial barcode spots

from DAPI cycle

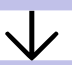

Segment barcode spots from hybridization cycles

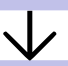

Segment fiducial barcode spots from hybridization cycles

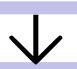

Calculate drift from fiducial barcode

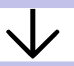

Aligns barcodes spots from hybridization cycles

$\downarrow$

Segment RNA signal

Create "Results" structure

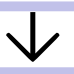

Assign detected readouts

to the segmented nuclei

Save workspace
Fit 3D gaussian on pre-segmented spots

Fit 3D gaussian on pre-segmented spots

Drift correction quality check

Assess results quality 
a

Center buttons

\begin{tabular}{|l|l|l|l|l|}
\hline Read new ROI & process & reSegment & replot & save data \\
\hline
\end{tabular}

\section{Processing options}

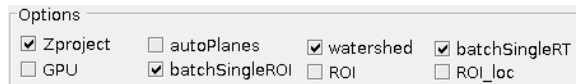
$\square$ profileNormalisation

\section{Image parameters}

Imagesettings

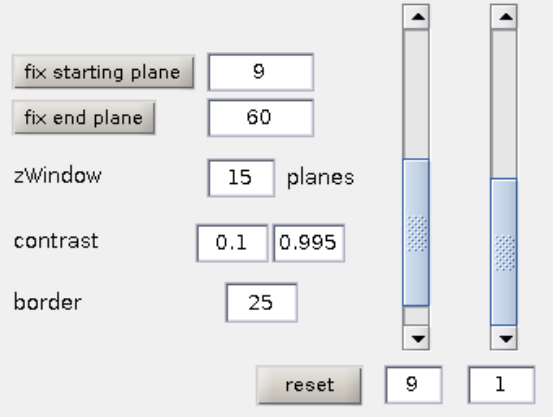

\section{Segmentation parameters}

Segmentation

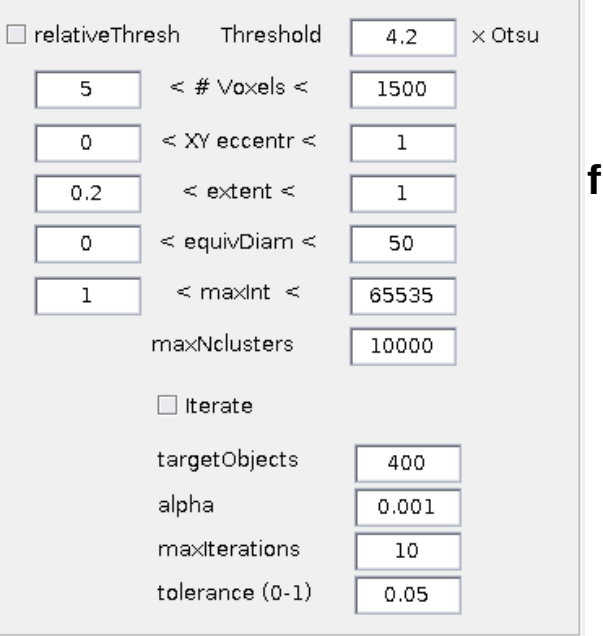

b

ROI selection bar

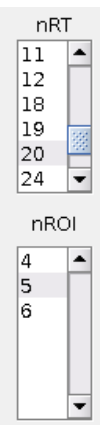

d

\section{Spot detection output}

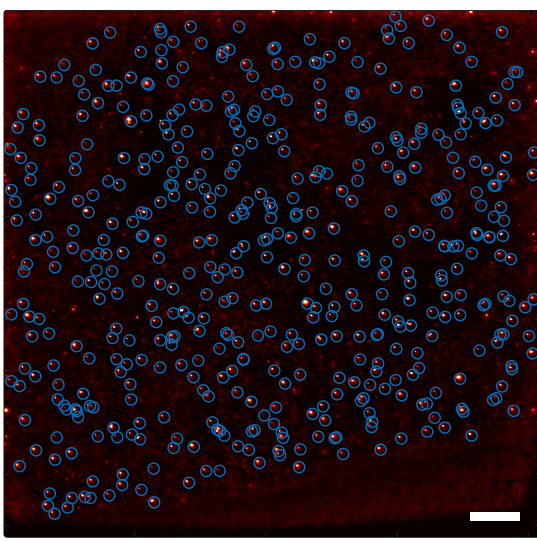

e

RNA segmentation pop-up window

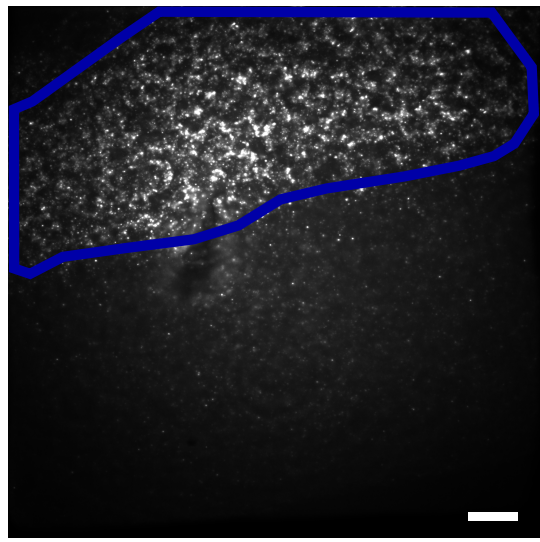

C

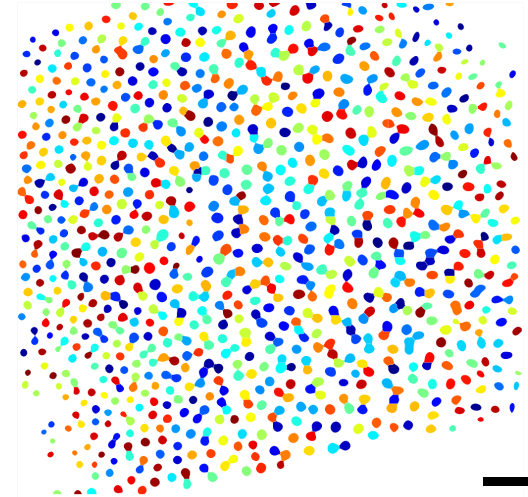

\section{Drift correction quality}
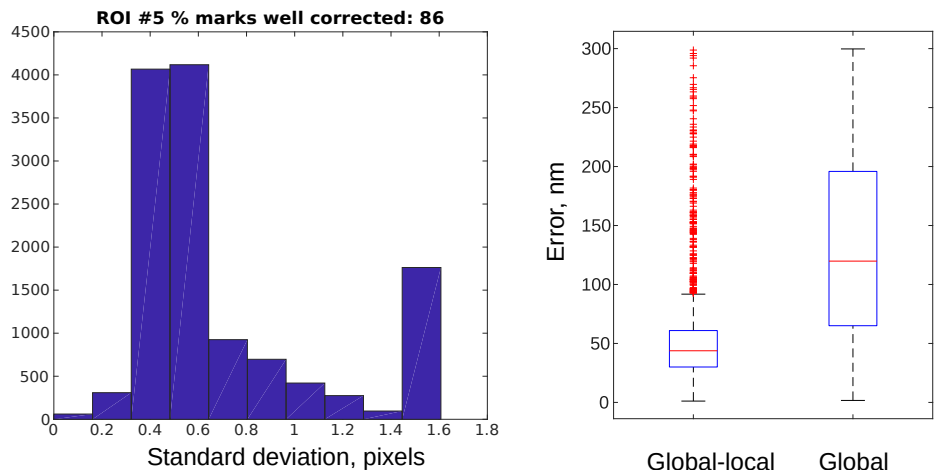


\section{Figure 9}

a
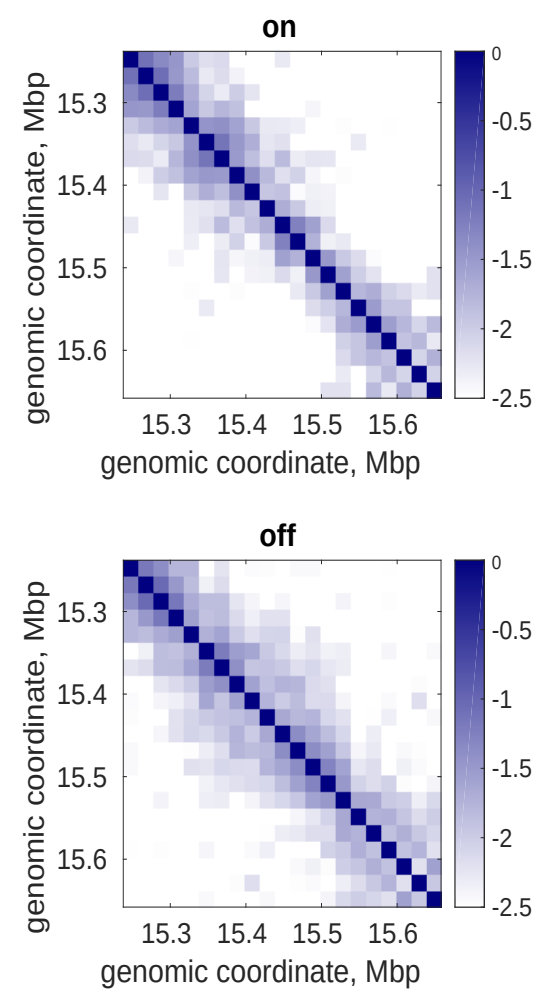

b
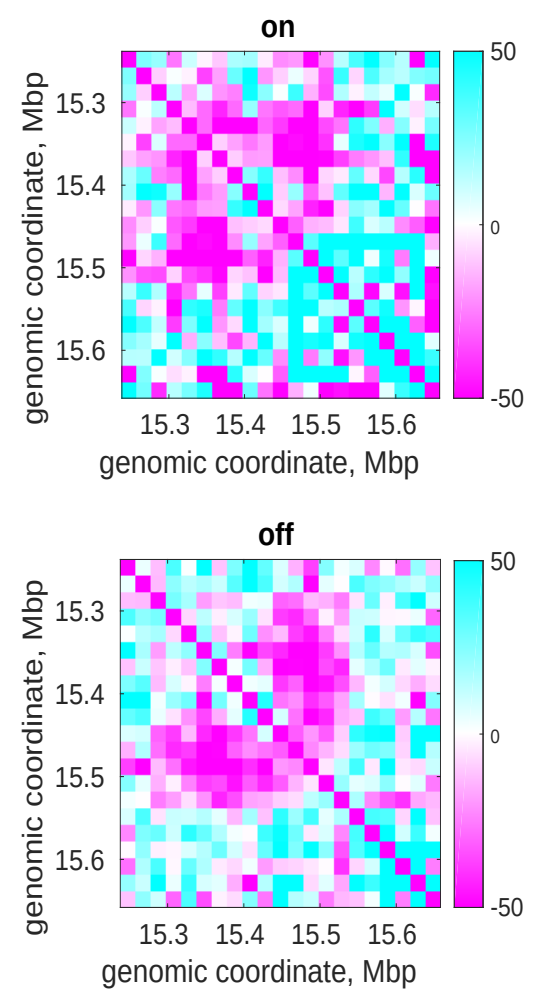

C

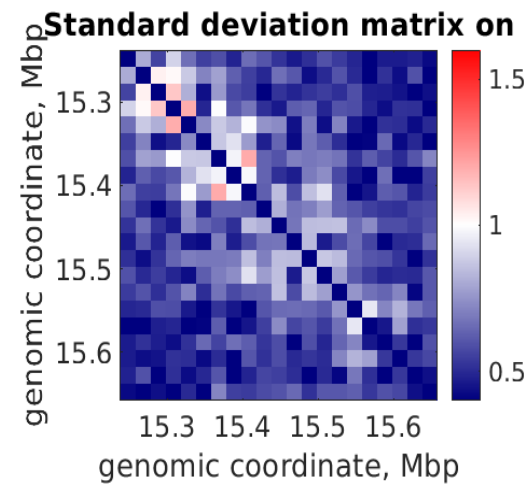

Standard deviation matrix off

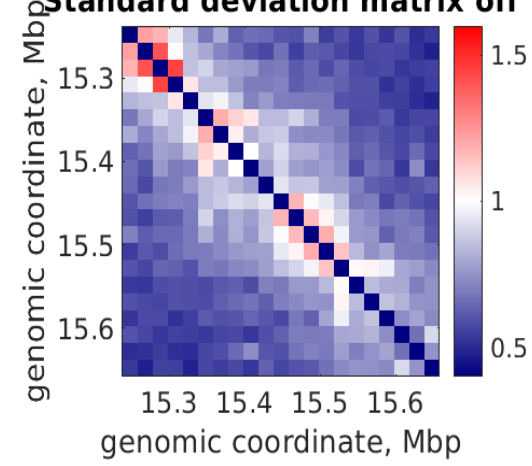

